\title{
Factors affecting staff demand for an electronic course materials service
}

\author{
by
}

\section{Upeksha Sajeevani Amarathunga}

Submitted to the School of Information Management,

Victoria University of Wellington

in partial fulfilment of the requirements for the degree of

Master of Library and Information Studies 
VICTORIA UNIVERSITY OF WELLINGTON

Te Whare Wānanga o te Ūpoko o te Ika a Māui

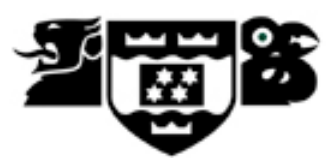

\section{MASTER OF LIBRARY AND INFORMATION STUDIES \\ LIBR 580 RESEARGH PROJEGT}

PLEASE FILL IN AND RETURN WITH THE 2 COPIES OF YOUR COMPLETED PROJECT

NAME: Upeksha Sajeevani Amarathunga

RETURN ADDRESS FOR PROJECT: 6/226 Greenlane Road, Greenlane West

Epsom, Auckland

PROJECT TITLE: Factors affecting staff demand for an electronic course

materials service

Supervisor: Alastair Smith

ENROLLED: Trimester 3\&1 year 2009

OFFICE use

PROJECT RECEIVED

PROJECT RETURNED

FILE 


\title{
VICTORIA UNIVERSITY OF WELLINGTON \\ School of Information Management
}

\author{
Master of Library \& Information Studies
}

\author{
IMPORTANT DISCLAIMER
}

with respect to a MLIS Research Project (INFO 580)

\section{Factors affecting staff demand for an electronic course materials service}

\section{(hereafter referred to as 'The MLIS Research Project')}

being undertaken by

\section{Upeksha Sajeevani Amarathunga}

in partial fulfilment of the requirements of the degree of

Master of Library and Information Studies,

School of and Information Management, Victoria University of Wellington.

\section{Topic Commencement: November 2008}

1. Victoria University of Wellington and its Council, its members, staff, employees, students and agents undertake no duty of care in contract, tort, or otherwise, to users (whether direct or indirect) of the MLIS Research Project and make no warranties or representations of any kind whatsoever in relation to any of its contents.

2. The MLIS Research Project is only made available on the basis that all users of it, whether direct or indirect, must take appropriate legal or other expert advice in relation to their own circumstances and must rely solely on their own judgement and such legal or other expert advice.

3. Under no circumstances will Victoria University of Wellington and its Council, its members, staff, employees, students or agents be liable in any way whatsoever, whether in contract, tort (including negligence), for breach of any statutory or regulatory duty (to the fullest extent permissible by law), or otherwise, to any user (whether direct or indirect) of the MLIS Research Project for any loss or damage whatsoever arising directly or indirectly as a result of the use in any way of the MLIS Research Project.

4. Each exclusion in the clauses of this disclaimer and each protection given by it is to be construed as a separate exclusion applying and surviving even if for any reason any of the exclusions or protections are held inapplicable in any circumstance. 
VICTORIA UNIVERSITY OF WELLINGTON

Te Whare Wänanga o te Ūpoko o te Ika a Māui

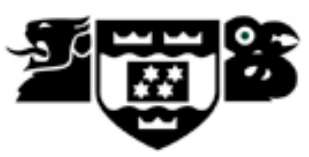

School of Information Management

\section{Statement of Availability INFO 580 Research Project}

Copies of Master of Library \& Information Studies research projects are retained in the School's research project collection, which is managed by the University Library. The author grants to the School of Information Management the right to list bibliographic details and abstracts of the projects in publicly available databases. Papers submitted in electronic form may be made available by the school on a network server. The author retains all rights to publish and/or sell the research paper by any means at any time.

The author states that the project does not violate any copyright or rights of others.

Student (Author): Upeksha Sajeevani Amarathunga

Supervisor: Alastair Smith

Project Title: Factors affecting staff demand for an electronic course

materials service

Year Project completed: 2009

I agree to the above conditions

Signed:

Date: 


\section{Table of Contents}

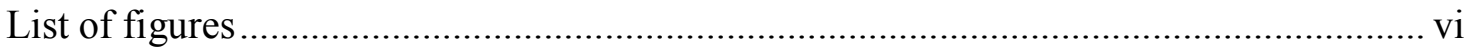

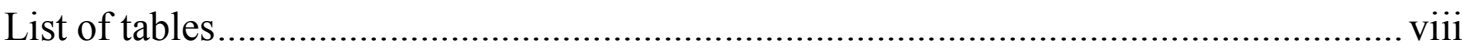

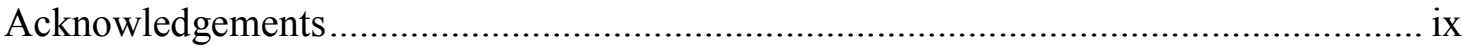

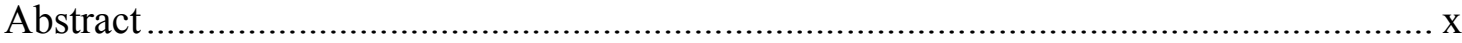

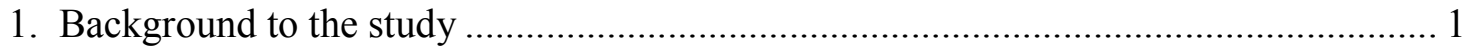

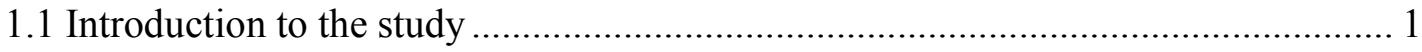

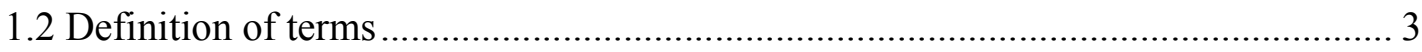

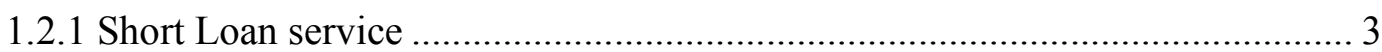

1.2.2 Electronic Course Materials service (ECM) ................................................... 3

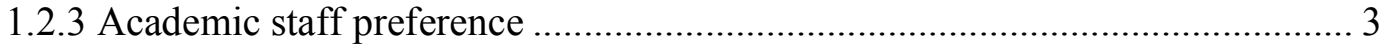

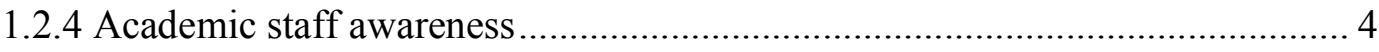

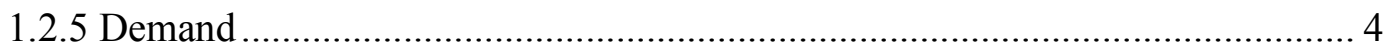

1.3 Background of the ECM service of the University of Auckland Library ................ 5

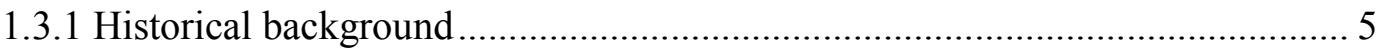

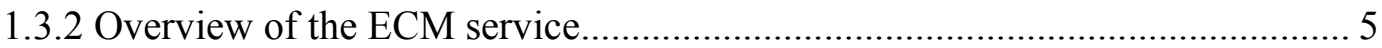

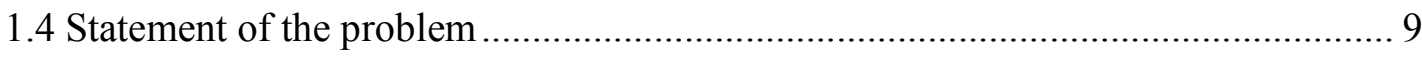

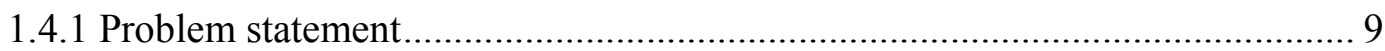

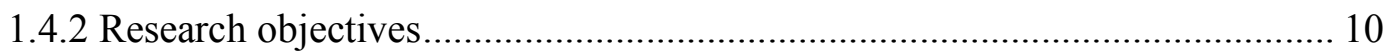

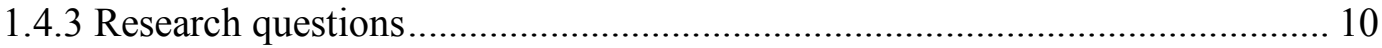

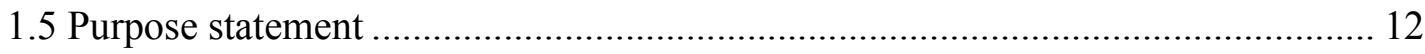

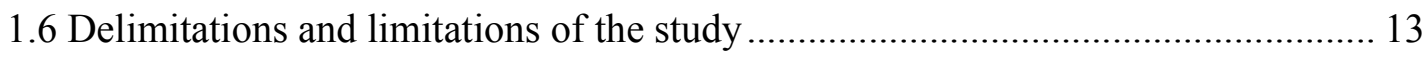

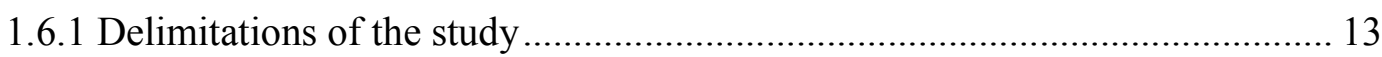

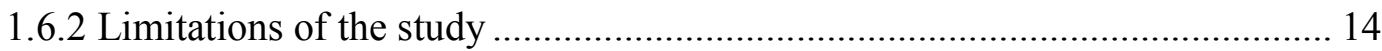

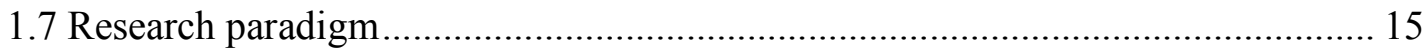

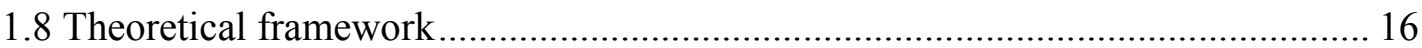

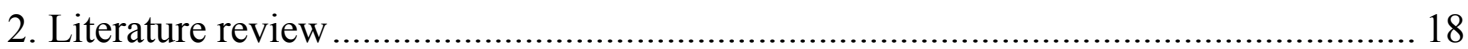

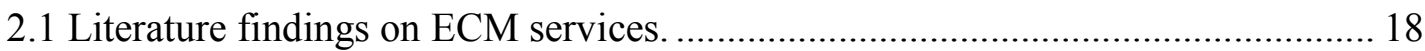

2.1.1 Literature related to students and the ECM service ....................................... 19

2.1.2 Literature related to librarians and the ECM service ................................... 21

2.1.3 Literature related to academic staff members and the ECM service ............... 22 
2.2 Critique of the literature

2.2.1 Gaps in the research on the ECM service

2.2.2 Critique of literature on research done on the 3 main stakeholders of the ECM service 25

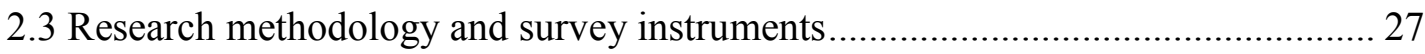

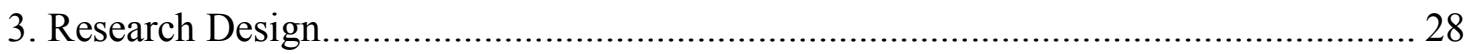

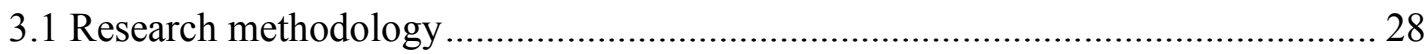

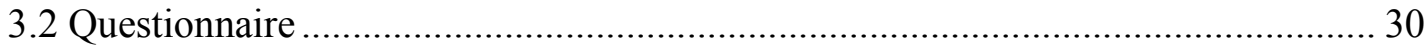

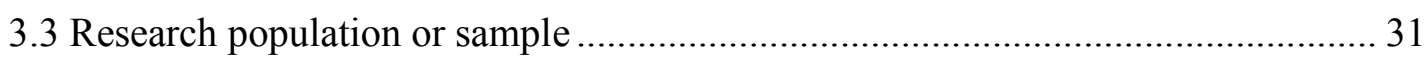

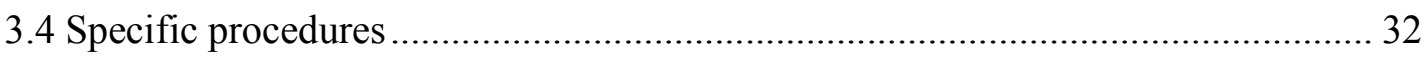

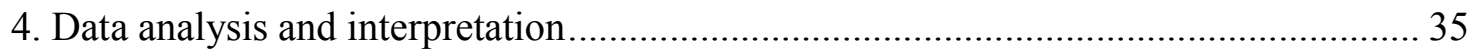

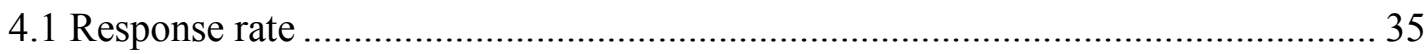

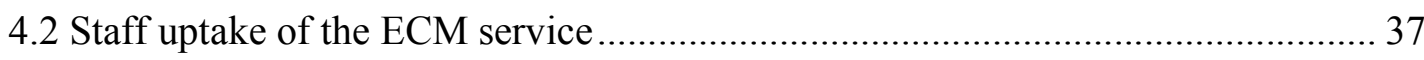

4.3 The relationship between the academic staff awareness of the ECM service and the demand for the ECM service

4.4 The effectiveness of the promotional plan of the ECM service in each department

4.5 The relationship between the academic staff preference for the ECM service and the demand for the ECM service

4.6 The relationship between the timeliness of the ECM service and the demand for the

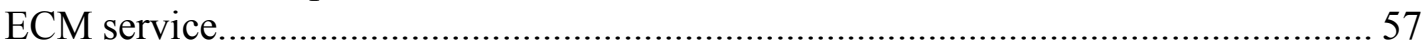

4.7 The relationship between the restriction on the types of materials that can be digitized through the ECM service and the demand for the ECM service.....

4.8 The relationship between the number of online or long distant courses delivered by academic department / unit and the demand for the ECM service .............................. 64

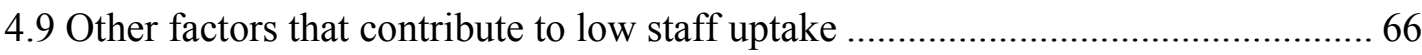

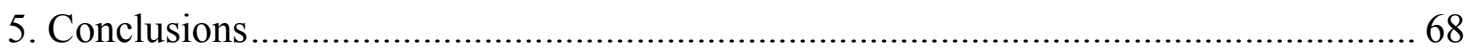

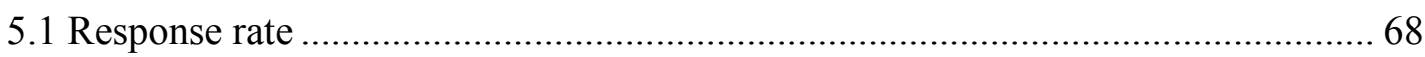

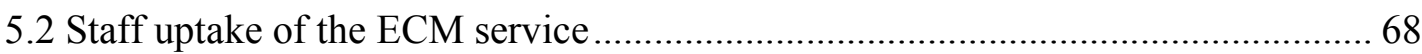

5.3 The relationship between the academic staff awareness of the ECM service and the demand for the ECM service

5.4 The effectiveness of the promotional plan of the ECM service in each department 
5.5 The relationship between the academic staff preference for the ECM service and the demand for the ECM service

5.6 The relationship between the timeliness of the ECM service and the demand for the ECM service.

5.7 The relationship between the restriction on the types of materials that can be digitized through the ECM service and the demand for the ECM service 72

5.8 The relationship between the number of online or long distant courses delivered by academic department or unit and the demand for the ECM service ............................ 73

5.9 Other factors that contribute to low staff uptake ................................................. 73

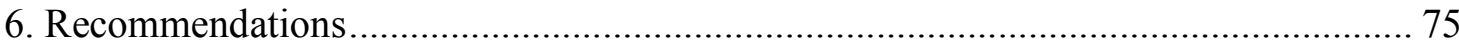

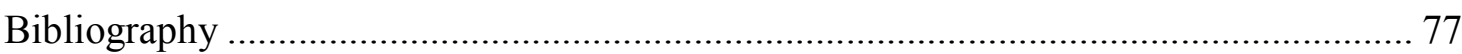

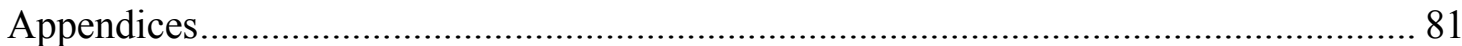

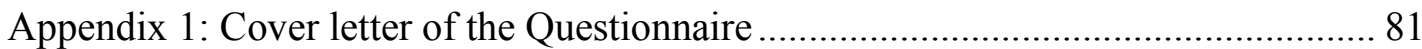

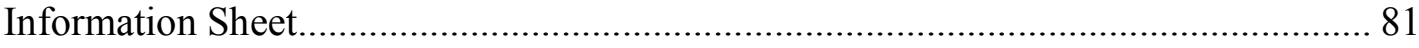

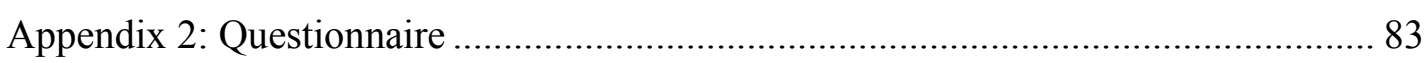

Appendix 3: First and Second Reminder emails...................................................... 86

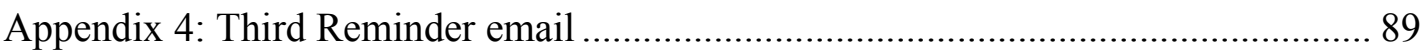

Appendix 5: Different types of course materials required for different subject areas .. 92 


\section{List of figures}

Figure 1: The number of responses received from each academic unit that were selected for the study

Figure 2: The number of ECMs digitized per course offered by different academic units, or departments of the University of Auckland in the academic year 2008

Figure 3: The number of academic staff members who were aware of the ECM service in different academic departments / units selected for the current research

Figure 4: The extent of academic staff awareness and the usage of the ECM service to digitize course materials 43

Figure 5: The number of academic staff members who became aware of the ECM service through Subject Librarians of the University of Auckland, Library Website, or through other academic staff members of the University of Auckland 46

Figure 6: Percentage of academic staff members who became aware of the ECM service through Subject Librarians, Library Website, or other academic staff members and used the ECM service to digitize course materials for their courses 48

Figure 7: Correlation between the number of requests made by Subject Librarians and the total number of requests made to digitize course materials between January 2009 and end of March 2009 50

Figure 8: Overall preference for the different methods of providing access to course materials

Figure 9: The number of academic staff members who agreed or disagreed that the ECM service makes course materials available promptly 
Figure 10: The number of responses received from academic staff members on the different types of course materials that are needed to be distributed to students

Figure 11: Relationship between the number of Out of Campus courses offered in each academic department / unit and the number of ECMs that were digitized through the ECM service per total number of courses offered by each academic department / unit 


\section{List of tables}

Table 1: The number and percentage increase in the total number of accesses of ECMs digitized by the University of Auckland Library 37

Table 2: The number of staff members who were aware that it was possible to digitize course materials through the library

Table 3: Total number and the percentage of degree of awareness of the ECM service among the academic staff members

Table 4: The number of staff members who became aware of the ECM service through Subject Librarians, Library Website, or other academic staff members who used the service

Table 5: The total number of requests received to digitize course materials and the number of requests that the Subject Librarians submitted for each academic unit / department between January 2009 and end of March 2009

Table 6: The overall preference for different methods of providing access to course materials per total number of responses received from academic staff members in different disciplines

Table 7: Relationship between the number of Out of Campus courses offered in each academic department / unit and the number of ECMs that were digitized through the ECM service per total number of courses offered by each academic department / unit ..65 


\section{Acknowledgements}

First and foremost I gratefully acknowledge my research supervisor Alastair Smith, Senior Lecturer of the Victoria University of Wellington, who provided me with advice, guidance, and assisted me whenever I encountered difficulties. His constructive feedback, thoroughness, patience and encouragement have enabled me to complete this research.

I am extremely thankful to Lynley Stone, Senior Tutor of the Victoria University of Wellington for her support and guidance which was invaluable for this study.

Thanks to Helen Renwick, Associate University Librarian, University of Auckland; Hester Mountifield, Assistant University Librarian, Information Commons \& Learning Services, University of Auckland; Ursula Loots, Short Loans Manager, University of Auckland for their time, knowledge and wisdom.

I am thankful to Nina Vasiljevic, Library Assistant Short Loans, for proof reading.

I would like to thank all the participants of the survey for the taking time to complete the questionnaire, and provide invaluable feedback. I also thank the Subject Librarians whom I consulted for their responses that were useful for this study.

I would like to express my appreciation to John Roder, Senior Lecturer of the Faculty of Education, University of Auckland and Nick Konings, Graphic Designer/Editorial of the Center for Education Design and Development (CEDD) of the Faculty of Education, University of Auckland, for providing invaluable information on the scanning service that they provide for online courses offered by the Faculty of Education, University of Auckland.

Finally, a special mention goes to my husband, Chaminda Amarathunga for proof reading, performing household tasks, childcare responsibilities and moral support. 


\begin{abstract}
Additional reading materials that are prescribed for undergraduate and postgraduate courses offered by the University of Auckland have a high demand. The Electronic Course Materials (ECM) service of the University of Auckland Library digitizes and provides online access to such materials. The demand for the ECM service varies between different staff members. Thus, this research project aims to investigate the factors affecting the staff demand for the Electronic Course Material (ECM) service provided by the University of Auckland Library.
\end{abstract}

The current research revealed that

- percentage increase in usage of the ECM collection in 2008 was less significant than that in 2007

- there is a correlation between the academic staff awareness and the staff uptake of the ECM service

- only $50 \%$ of the staff members who were aware of the ECM service used the service to digitize course materials

- subject Librarians play an important role in promoting the ECM service in academic departments / units that had a high staff uptake

- the Library ECM webpage was less significant in promoting the ECM service

- the University of Auckland Library does not have a standard method of promoting the ECM service throughout all the academic departments / units

- most preferred method of providing access to course materials was through nDeva, Cecil and WebCT. The ECM service was the third preferred method

- there was no relationship between the timeliness of the ECM service, restriction on the types of materials that can be digitized through the ECM service, availability of distant or online courses and the staff uptake of the ECM service

Recommendations mentioned in page 61 were made based on these findings. 


\section{Background to the study}

\subsection{Introduction to the study}

Additional reading materials are prescribed for most of the undergraduate and postgraduate courses offered by the University of Auckland to encourage constructivist learning. These recommended reading materials have a high demand, and one of the important functions of the University of Auckland Library is to provide efficient access to these materials.

Academic staff members distribute course materials through:

- virtual Learning Environment Software and Course Management Systems such as WebCT, Cecil and nDeva

- the Electronic Course Materials (ECM) Service provided by the Library

- hardcopy course materials through Library Short Loan Collection

- course reading packs

- the Center for Education Design and Development (CEDD) of the Faculty of Education

- distributing reading materials in class

- course pages created by subject librarians of the Library

The ECM service of the University of Auckland Library digitizes and provides online access to course materials to provide efficient access to course materials. There are significant differences in demand for the ECM service, for example, between different subject areas (discussed in detail under 4.2). Despite this, there has been no research to determine the reason for this variation. Thus, it is necessary to investigate factors that influence teaching staff uptake of the ECM service of the University of Auckland Library. 
Factors that may hinder the uptake of the ECM service by different departments include:

- restriction on the types of materials that can be digitized through the ECM service (discussed in detail under section 4.7)

- availability of service other than the ECM service that the academic staff members prefer to use over the ECM service of the Library (discussed in detail under section 4.5)

- effectiveness of the promotional plan of the ECM service to promote and create awareness of the ECM service among all the academic staff members of the University of Auckland (discussed in detail under section 4.3, 4.4)

- inability to provide access to course materials promptly through the ECM service (discussed in detail under section 4.6)

This research project aims to determine whether the above factors have an impact on the variation in the demand for the ECM service. These findings can be used to improve the ECM service and to enhance the demand for the service. 


\subsection{Definition of terms}

\subsubsection{Short Loan service}

Students who are enrolled in tertiary education institutions get recommend, prescribed, and further reading material from core text books, journals, etc. There is a high demand for these materials. Therefore, libraries of academic institutions maintain collections of such text books, journals, etc. containing reading materials that have a high demand. This service is referred to as the Short Loan service at the University of Auckland.

\subsubsection{Electronic Course Materials service (ECM)}

The World Wide Web provides the ability to host high quality multimedia learning materials such as text, pictures, video and audio. This ability has transformed the method of providing access to digital material (Hill \& Hannafin, 2001) such as course materials in academic libraries (Caplow, 2006, p.165). This service, provided by academic libraries, is known as "Electronic Course Materials (ECM) service," or OpenCourseWare (OCW) service (Kirkpatrick, 2006), or web-based course material service (Guler \& Istanbullu, 2004, p.447), or electronic reserve system (Pilston \& Hart, 2002, p.147). In this report this service will be referred to as the ECM service.

\subsubsection{Academic staff preference}

The academic staff members of the University of Auckland can provide access to course materials through a variety of ways. The phrase "academic staff preference" refers to whether they desire the ECM service over the other methods that are available mentioned in 1.1. 


\subsubsection{Academic staff awareness}

The University of Auckland Library promotes the ECM service to academic staff members through the following methods:

- subject librarians advertise and encourage the academic staff members to use the ECM service

- the Library webpage

This research project will determine whether the academic staff members are conscious about the services that are provided through the ECM service. The phrase "academic staff awareness" will be used to refer to the fact whether or not the academic staff members are cognizant that the ECM service exists.

It is possible to enhance the demand for the ECM service by promoting the service to students. When students are aware of the service and use it, lecturers are more likely to submit materials to the ECM service to digitize materials. However, whether or not students are aware of the ECM service will not be considered in the current study due to time limitations.

\subsubsection{Demand}

There are several services (mentioned under 1.1) that the academic staff members of the University of Auckland use to provide access to course materials. Academic staff members may prefer some services over other services. The degree of inclination of academic staff members to use the ECM service can be reduced because of the availability of other services. The number of requests received to digitize course materials through the ECM service gets affected by the availability of other services that produce course materials. The demand for the ECM service is the number of course materials digitized through the ECM service. 


\subsection{Background of the ECM service of the University of Auckland Library}

\subsubsection{Historical background}

Until 2004, Short Loan service of the University of Auckland Library lent photocopied articles and chapters of books on desk copy for students. This system was changed in 2004 so that all such items were digitized and made accessible for students online. This service is known among staff of the University of Auckland Library as the Electronic Course Materials service. Using an online form academic staff members submit requests to digitize course materials for their courses. The number of requests received to digitize course materials expanded exponentially (refer 4.2 for more information) due to the advantages of the service (mentioned under 2.1.1). Initially, the requests submitted to digitize were administered by maintaining an Excel spreadsheet. This spreadsheet was useful to keep track of the requests received, and to obtain basic statistics of the requests received, as well as the turnaround time to digitize them. However, maintaining the spreadsheet was time-consuming because staff had to manually transfer the information from the online request form to the spreadsheet. Space limitation meant it was not possible to transcribe all communications between the requester and Short Loan staff. For this reason, a database was created to track the requests received to digitize course materials (described in 1.3.2).

\subsubsection{Overview of the ECM service}

The Electronic Course Materials Service makes prescribed and recommended journal articles, book chapters, book extracts, conference papers, case law, and parliamentary material available online for student course work for all subject areas. The service provides a centralized service for the submission, processing, production and copyright management of reading for all subject areas (University of Auckland, 2009).

Currently, the academic staff members, divisional library staff, and subject librarians place their requests to digitize course materials via an online form on the Library Webpage. The details of the requester of the ECM get automatically populated in the current request forms. All the requests are captured into a database called Course 
Material Request Administration Database. This database tracks and records details of all short loan requests for electronic and hard copy materials submitted via the online request form. The Course Material Request Administration Database provides a universal requesting process where requests submitted can be easily tracked and confirmed for the requesting faculty member and the ECM service staff.

There are two basic types of Electronic Course Materials

- materials that are in hardcopy format, such as chapters or extracts from books, journal articles or conference proceedings. If the hardcopy of the item is available on the shelves of the Library, they are digitized without any delay. Items that are on loan have to be recalled from patrons before the required pages can be digitized. If an item is not held by the Library, or if it is out of print, the material is obtained via interloan.

- existing electronic documents such as full-text database articles, WebPages, and conference reports that can be accessed electronically. These materials are not deposited in the ereserves collection. The materials are linked directly to the required course lists.

Once a request is received to digitize a course material the copyright compliance is checked against the standard copyright license. The copyright license from the Copyright Licensing Ltd permits copying the following extracts from books, periodicals, and journals (University of Auckland, 2009):

- up to $10 \%$ or one chapter of a work, whichever is larger

- up to 15 pages of a single work in a collection of works if the work is published separately

- up to one article from a periodical publication and additional articles if they are on the same subject 
When academic staff members wish to digitize material exceeding the above limits, they are responsible to obtain permission from copyright holders, and complete a Copyright Warranty Consent Form, before the material is digitized for the course.

"The copyright license described above does not include copying from full-text database articles, electronic journals and electronic books. The Library and various departments within the University purchase the right to use copyright material contained in electronic databases. The terms under which these databases are purchased determine the uses the University can make of them. Therefore the right of staff and students to copy and use this material will vary according to those terms. The majority of licenses do not permit multiple copies of the database materials to be made and distributed to students. Before copying and/or distributing material from such databases, advice must be sought from the Library or department which hosts the database. Normally the best practice is to give other staff and students the electronic address for the relevant information, allowing them to access the materials directly from the database site themselves" (University of Auckland, 2009).

When requests are received by the ECM service to provide links to full-text database articles, electronic journals, and electronic books, a stable link is provided to the material enabling the students to directly access the material.

The processing time for ECMs depends on the availability of the original book, journal, or report. The ECM team aims to complete requests where the item is immediately available (on the library shelves) within 5 working days from the date of submission. A large number of requests are received just before each academic semester. The requests received to digitize are processed according to the order in which they were received. The volume of requests received affects the turnaround time to digitize the requested material (University of Auckland, 2005). 
The University of Auckland Library uses the Exlibris Voyager Library System. The digitized ECMs are linked to Course Reserves Lists in the Reserves module within the Exlibris Voyager Library Management System. The students, academic staff members, and the librarians can access these ECMs that are linked to the Exlibris Voyager Library System through Course Materials search in the University of Auckland Library Webpage or through the Course Materials Search tab in the Library Catalogue. Course materials are displayed alphabetically by the title of the material. The library provides restricted access to the digitized material to members of the University of Auckland through an authentication system to prevent external users from gaining access to copyright controlled ECMs in the collection.

Many Subject Librarians have started maintaining Course Resource Pages. They provide links to electronic course materials digitized through the ECM service directly from Course Resource Pages because of the greater flexibility these pages offer. Course Materials can be displayed in any order, by lecturer, lecture number, week, topic, etc. on Course Resource pages (University of Auckland, 2005).

Annually, at the end of each academic year, lists of ECMs and the number of times that they were accessed are compiled for each course offered during the academic year and are circulated to Subject Librarians. The Subject Librarians send them to academic staff members who taught the course, informing them to indicate which course materials they want to retain for the next year. The course materials that are not needed for the next year are removed from course reserves lists. The materials that are removed are reinstated on request. This process is referred to as the Annual Weeding process. 


\subsection{Statement of the problem}

Statistics of the University of Auckland Library (discussed under section 4.2) shows that there is a high variation in the demand for the ECM service for different subjects offered by the University of Auckland. This can be due to various reasons (mentioned under $1.1)$.

However, research has not been done to determine whether the following factors have an effect on the demand for the ECM service:

- the user friendliness of the system

- academic staff awareness and preference

- availability of software and services other than the ECM service

- timeliness of the ECM service

- number of long distance and online courses offered by academic departments

- need to provide access to different types of course materials required for courses taught in each department

Thus, to enhance the ECM service, and to attract academic staff members it was necessary to carry out research to seek information on departmental requirements for core course materials, and their current practices and attitudes towards providing material in electronic format.

\subsubsection{Problem statement}

The aim of the current research is to determine the factors that affect the staff demand for the ECM service provided by the University of Auckland Library. 


\subsubsection{Research objectives}

This research project aims to investigate

- the relationship between the academic staff awareness of the ECM and the demand for the ECM service

- the effectiveness of the promotional plan of the ECM service in each department

- the relationship between the academic staff preference for the ECM service and the demand for the ECM service

- the relationship between the timeliness of the ECM service and the demand for the ECM service

- the relationship between the restriction on the types of materials that can be digitized through the ECM service and the demand for the ECM service

- $\quad$ the relationship between the number of online courses delivered by academic staff members and the demand for the ECM service

\subsubsection{Research questions}

- To what extent does the academic staff awareness of the ECM service vary between different departments of the University of Auckland?

- To what extent does the academic staff awareness of the ECM service contribute to the demand of the ECM service?

- To what extent does the effectiveness of the promotional plan of the ECM service contribute to the demand of the ECM service?

- To what extent does the academic staff preference for the ECM service vary between different departments of the University of Auckland?

- To what extent does the academic staff preference for the ECM service contribute to the demand for the ECM service?

- To what extent does the timeliness of the ECM service contribute to the academic staff preference for the ECM service? 
- To what extent does the ability to provide access to all types of course materials through the ECM service contribute to the academic staff preference for the ECM service?

- To what extent does the number of online courses offered by each department contribute to the demand for the ECM service? 


\subsection{Purpose statement}

This research is useful for the following reasons

- as a preliminary investigation on factors that influence academic staff satisfaction with the ECM service

- to ensure that the service caters effectively to the needs of academic staff members

- to provide recommendations to improve the ECM service provided by the Library

- to provide an indication of the degree of acceptance of the ECM service in the academic environment in the New Zealand context

- ECM services are well established in many universities throughout the world.

However, only a limited amount of research is available on the factors responsible for the effectiveness of the ECM service

- this research will provide a model that can be used to replicate this type of research in other universities throughout the world 


\subsection{Delimitations and limitations of the study}

\subsubsection{Delimitations of the study}

- This is a case study that focuses on the ECM service provided by the University of Auckland Library. It is necessary to compare these types of services provided by different institutions to obtain a better understanding of the factors that impact the academic staff awareness of and preference for the ECM service. A delimitation of the study is that it is not possible to integrate other institutions into the current study due to time limitations.

- Although it is possible to ascertain people's thoughts, opinions, feelings and beliefs about the ECM service (Hair et al., 2003) through interviews with academic staff members, interviews have not been used as a research tool for the current research due to time limitations.

- According to extant literature, in many pieces of research done to evaluate the student satisfaction with online course reserves, online and paper-based surveys had been used (Biktimirov \& Klassen, 2008, p.154, Lowell, Christopher \& Jeff, 2003 and Isenberg, 2006, p.167). This enables obtaining responses from stakeholders who prefer to complete survey questionnaires in both electronic and hardcopy formats. However, due to resource and time limitations questionnaires have been sent to academic staff members only in electronic format.

- Ten academic staff members were selected from each of 13 academic units of the University of Auckland. These 13 academic units offered courses that required different types of course materials, different number of distance courses, and different number of courses offered per each academic year. The total number of academic staff members selected from each academic unit was not proportional to the number of courses offered by each academic unit, or the total number of academic staff members in each academic department / unit. Some academic 
departments / units such as Music, Dance, and Fine Arts are very small, compared to Arts and Education. In general, the response rate for questionnaires can vary between 10-60\% (Sudman \& Blair, 1998, p. 165). If the research sample had been selected based on the department / unit size, there would have been a high probability that responses would have not been received from small departments. One of the main objectives of the study was to determine whether the restrictions on the types of materials that can be digitized had an impact on the staff uptake of the ECM service. Academic departments / units such as Music, Dance, and Fine Arts could have different expectations from the ECM service. Thus, ten academic staff members from each department / unit were selected to ensure responses from all the academic units. This guarantees a better perception of the reason for variation in staff uptake of the ECM service from all the academic units.

\subsubsection{Limitations of the study}

It is possible to increase the demand for the ECM service by promoting the service to students, because when students are aware of the service and use it, lecturers are more likely to submit materials to the ECM service to digitize materials. However, the demand for the ECM service by students is not considered for the current study due to time limitations. 


\subsection{Research paradigm}

There are 3 approaches to social science research. They are positivism, Interpretive Social Science (ISS), and Critical Social Science (CSS) approaches. Positivism is associated with many social theories that seek rigorous, exact methods to measure precise quantitative data to test a hypothesis (Neuman, 2003). Positivists use quantitative research methods that are often used to describe trends and explain the relationship among variables by analyzing numbers using statistics (Creswell, 2002). In the current study, the attitude of the academic staff members towards the ECM service will be studied. Although this can be quantified, it will be useful to include qualitative analytical techniques, as well as qualitative analytical techniques to get a better perception of the academic staff awareness, preference, and the attitude towards the ECM service. Thus, this method is not suitable for the current research.

On the other hand, Critical Social Science theory takes an extreme approach to social science research, where the researcher first identifies a specific organization of people whose needs are not satisfied with the current system, then enters the participant's world to gain an interpretive understanding of the situation (Willis, 2007, p.60). To carry out the research under Critical Social Science theory, the researcher would have to gain an understanding of each course taught in the University of Auckland. This is not feasible due to time limitations. Therefore, this method is also not suitable for the current research.

Interpretive approach is the "systematic analysis of socially meaningful action through the direct detailed observation of people in natural settings in order to arrive at understandings and interpretations of how people create and maintain their social worlds" (Neuman, 2003, p.76). Consequently, Interpretive Social Science is called a qualitative method of studying meaningful social activities with a purpose. One of the objectives in the current research is to determine the attitude of academic staff members towards the ECM service. In this research project human behavior towards the ECM service will be studied in detail. Therefore, interpretive approach is suitable for this research project. 


\subsection{Theoretical framework}

The Task-technology Fit (TTF) model and the Technology Acceptance Model (TAM) were selected for this research project. "TTF model considers the degree to which the capabilities of technology match the demands of a task" (Lin \& Huang, 2008, p.410).

Dugdale (1998, p.133) states that it has become increasingly difficult to meet the demand for traditional print sources in tertiary education institutions. In addition, the traditional short loans collections have the following barriers:

- inability to provide 24 -hour access to course materials

- inability to provide multiple access to a single copy at a given time

- inability to provide efficient access to course material due to malicious hiding of physical items

- inability to provide remote access to course materials

The TTF model is useful for this study because the ECM service utilizes the potential of new technology to provide simultaneous, remote and online access to course materials.

There are four main constructs in the TTF model (Chang, 2008, p.567)

- task characteristics - the ECM service should have the ability to provide efficient and timely access to course materials.

- technology characteristics - the ECM service should be able to provide efficient and timely access to different types of course materials required for different courses using new technologies.

- utilization and performance - task characteristics and technology characteristics affect the performance and utilization of the new system.

TAM states that there is a connection between the acceptance of different information technologies and the users' perception on their final decision to use the new technology 
(Chang, 2008, p.564). Since the ECM service was established in 2004, there has been a significant increase in the collection size of the ECM collection of the University of Auckland Library. However, the demand for the service varies considerably between different departments of the University of Auckland. This research aims to find out whether the ECM service is universally accepted by all the academic staff members of the University of Auckland, regardless of whether they are early or late adopters of technology. In this study, the attitude regarding the ECM service of randomly selected sample of academic staff members comprising both early adopter and late adopters of technology will be researched. Therefore, the TAM model is useful for this research.

The user attitudes regarding the ECM service will be positively affected if the ECM service has used new technology to deliver course materials efficiently. On the other hand, if the ECM service is not universally accepted by all the academic staff members of the University of Auckland, then the University of Auckland Library has to take actions to update the ECM service to cater for the needs of all the academic staff members. Thus, research had to be designed to determine whether the ECM service is generally accepted by all the academic staff members of the University of Auckland, whether user expectations are met from the service that is provided by the current ECM service, and whether it is possible to improve the ECM service using new technology. Therefore, both TTF and technology acceptance models are useful for this research. 


\section{Literature review}

\subsection{Literature findings on ECM services.}

The literature referred to in this review was identified from a range of sources. The most useful database was Library and Information Science Abstracts. Furthermore, databases such as Library and Information Science Fulltext, Expanded Academic ASAP, ProQuest (which includes ABI/Inform), EBSCO, Academic Search Premier, Lexis and Emerald were used. Although Te Puna and the online catalogues of Victoria University of Wellington and University of Auckland Libraries were searched for books and research documents, it was not possible to locate any research material related to the research area. Several search engines such as Google Scholar were also used to locate relevant literature.

This review covers a range of topics including:

- why it was necessary to digitize course materials and provide online access to them

- literature related to students, librarians and the academic staff members who are key stakeholders of the ECM service

There are numerous literatures that point out major concerns about the rapid growth in university student numbers (Brown, 1996, Dugdale, 1998, Feather \& Marriott, 1993). At present, there is a greater emphasis on open, distance, student-centered and active learning along with reduced staff/student contact hours. This has resulted in increased library use (Dugdale, 1998). Project work and student assignments demand more studentcentered work, and thus impact on demand for library resources (Dugdale, 1998). The parallel growth in modularization has had an even greater impact upon the tendency towards peak demand periods for some items. Several libraries have reported that high demand for some materials over short time periods had made it difficult for them to provide material both quickly and in sufficient quantities (Cockrill, 1997). One means of addressing the issue of too many students chasing too few texts over a limited period is 
the operation of a Short Loans Service. However, there are a large number of problems associated with the maintenance of large Short Loan Collections:

- it is necessary to rigorously weed out under used materials (Dugdale, 1998)

- use staff time intensively (Dugdale, 1998)

- accidental or deliberate mis-shelving of books by students (Dugdale, 1998)

- inability to have multiple copies of particular texts available at certain times (Secker, 2001)

- providing longer access duration for course materials (Secker, 2001)

Many of the problems associated with a traditional print Short Loan collection can be addressed by introducing an electronic resource base (Secker, 2001, p.35). Material which has been traditionally held in a Short Loan Collection can be entered into an electronic system and made readily available for a larger group of users during peak periods (Dugdale, 1998).

By digitizing course materials it is possible to provide flexible and easy access to course resources to teachers, students (Secker \& McAvinia, 2001, p.36), and librarians (Brinkman, 2004, p.10). Secker \& McAvinia (2001, p.36) state that effective development of the ECM service depends on a true partnership between those designing resources (librarians), and the staff and students who need the resources. As a result, to extend the ECM service it is important to find out whether the stakeholders (students, academic staff members and librarians) of the ECM service prefer to use the ECM service and are satisfied with the service.

\subsubsection{Literature related to students and the ECM service}

The students receive a large number of advantages when they are able to access course materials online. They are

- increased availability of resources by providing multiple-user, multiple location, twenty four hour a day and remote access (Dugdale, 1998 and Secker, 2001, p.34) 
- increased availability of resources in long distant courses (Secker, 2001, p.10)

- increased availability to non-traditional students, who may be unable to get to the library during opening hours (Secker, 2001, p.41)

- protection from theft and mutilation (Shapiro, 1995)

- ability to search for items is easier and faster (Dugdale, 1998)

- ability to access any number of items in addition to the library's borrowing allowance (Dugdale, 1998)

- ability to download and print for longer access (Dugdale, 1998)

Lowell, Christopher and Jeff (2003) analyzed the contrast between online and traditional delivery methods in terms of the impact on student learning and satisfaction for similar course materials. They discovered that there is no significant difference in satisfaction on online and traditional delivery methods. Students receive a large number of benefits when course materials are distributed electronically. Thus, more research has to be carried out to conclude this point.

There are some concerns among academics about providing online access to course materials. Secker argues that electronic delivery of course materials can

- $\quad$ spoon-feed students

- remove the need to learn how to use library collections

Investigations done by Isenberg (2006) on the degree of technical readiness, satisfaction, and preference of graduate students for online reserve readings have revealed that students prefer accessing course material online to accessing course material through traditional Short Loans Collections. Furthermore, in research done by Matthew and Varagoor (2001), and Pilston and Hart (2002) on student reactions to the required use of online course materials, it was found that students prefer online course reserves than inlibrary print course reserves. The student perception on whether course material were provided online or in hardcopy format is an important factor that academic staff members should consider when deciding whether to provide course material online or in hardcopy format. 
Caplow, 2006, and Kendall, 2001, have evaluated the overall placement of course materials in web-based course management systems (Caplow, 2006, p.166 and Kendall, 2001). They have classified course materials into Course Syllabus, the Course Content Materials, specific information about assignments, and web resources. Keefer, 2005, concludes that it is possible to enhance student learning by integrating course materials effectively into courses. Biktimirov and Klassen (2008) investigated the value of online support materials in hybrid courses and students' total hits on different types of course materials, such as solutions to homework problems, PowerPoint slides, etc. They concluded that access to course specific files such as homework solutions is more valuable than access to online course materials in general. Thus, it is important to be able to digitize course specific files through electronic reserves services.

If it can be established that the relatively low demand from some departments for the ECM service of the University of Auckland Library is due to the restrictions on types of materials that can be digitized through the ECM service, the above findings are useful to make recommendations to improve the ECM service to attract academic staff members of all the departments of the University of Auckland to use the ECM service.

\subsubsection{Literature related to librarians and the ECM service}

As discussed under 1.3.2 copyright is one of the issues that librarians have to deal with when maintaining an electronic reserves collection. Ferullo (2002) has evaluated the copyright issues related to providing online access to course materials. She concludes that although copyright law limits providing seamless online access to full-text material, the copyright law has tremendous opportunity and flexibility because of fair use exception. If it is established from the current research that staff uptake of the ECM service is affected by the restriction on the type of materials that can be digitized by the ECM service, the 
Library management should reconsider the limitations on the types of materials that can be digitized through the ECM service.

The ECM process has the following steps (Sewell, 2007, p.515),

- submitting requests to digitize course materials

- sourcing the item required for digitizing

- determining whether there are copyright issues related to the submitted request

- scanning and digitizing the document

- tracking and communication with the requesting faculty member

- making the digitized material available for the users

Brinkman, Lavallee-Welch \& Paul, 2004, and Laskowski \& Ward, 2001, p.361, have evaluated administrative issues, technical and workflow issues, issues related to education and training of students and academic staff members when establishing an electronic reserves software system. Their findings are useful to restructure the workflow of the ECM service to enhance its efficiency of digitizing course materials. Library, academic staff and students need practical training in the use of the system (Dugdale, 1998). The Library has to organize extensive training sessions with all the stakeholders of the ECM service not only to provide practical training of accessing the electronic reserves collections, but also to promote the electronic reserves collections.

\subsubsection{Literature related to academic staff members and the ECM service}

According to Sewell (2007, p.515), at the University of Denver's Penrose Library in the USA, there are many methods of providing access to course materials, which can lead to duplication of work and can become inconvenient for students, academic staff members, and library staff. Biktimirov and Klassen (2008, p.153) state that academic staff members can easily provide online access to course materials using pre-established course management systems such as WebCT and Blackboard. However, it was not possible to 
locate any research finding on whether the availability of pre-established course management systems influences the demand for the ECM service.

Sewell (2007, p.515) mentions that the time has come to formally collaborate with other service points in University of Denver's Penrose Library to effectively define, streamline, and provide a better service to the academics. This is an important fact that should be implemented in all the instances when the digitizing services are duplicated. The University of Denver's Penrose Library provides a good example of how to streamline digitizing services. They have created a Task Force that includes representatives from each of the stakeholders from the University Library, the campus bookstore, Blackboard, the Centre for Teaching and Learning, the University Technology Services, multimedia services and the faculty. Swell $(2007$, p.516) states that their ultimate goal was to create a universal requesting process, designed with the principle of ease of use and access by having forms automatically populated, sent out, tracked, and confirmed for the requesting faculty member.

Sewell (2007, p.515) states that at the University of Denver's Penrose Library, although the library staff received a lot of requests for their ECM service, most of the academic staff were not aware of the service. Therefore, it is important to have a proper communication plan to promote and create an awareness of the ECM service (Young \& Stokker, 2001). It is important to communicate the benefits of the ECM service to staff and students (Keefer, 2005). Therefore, to enhance the demand for the ECM service, librarians have an important role in promoting the ECM service (Brinkman, 2004, Dugdale, 1998, p.139 and Laskowski \& Ward, 2001, p.169).

Secker (2001) investigated

- how the required core materials differ between subject disciplines

- how the current teaching support services offered by library services of the University College London are used by departments and their attitude towards them 
- the existing digital initiatives within departments to improve access to core course materials.

This research identifies a range of reading materials that are used by different academic departments as core course materials. The survey has also revealed that a number of departments were using in-house systems to deliver course materials electronically. This is an issue that many universities with digitizing services are struggling to cope with. Furthermore, this research revealed that there are a number of requirements specific to individual departments and that effective ways of delivering course materials are essential for each department. These findings will be useful when interpreting results of the current research and making conclusions and recommendations for the current research. 


\subsection{Critique of the literature}

\subsubsection{Gaps in the research on the ECM service}

It was obvious that there is only a limited amount of research done on ECM services in general. The literature review revealed that there were only a few articles available in refereed journals. Secker also states that, in general, ECM services have been running in many universities around the world for a number of years, but only a limited amount of research has been done (Secker, 2001, p.14). The factors that can influence the staff uptake of the ECM service have not been fully explored. Furthermore, it was not possible to locate any research material on how the timeliness of the ECM service can contribute to the demand of the ECM service.

\subsubsection{Critique of literature on research done on the 3 main stakeholders of the ECM service}

- students - most of the research done on the ECM service concentrates on the reactions and attitude of students on the ability to access course materials online. Mostly, findings from this type of research are useful in making preliminary decisions on whether ECM services can satisfy the increasing demand for course materials.

- librarians - Research has been done on practical issues in establishing an ECM service. However, research is not available on the contribution of the overall timeliness of the ECM service and the restrictions of the types of materials that can be digitized on the staff uptake of the ECM service. Although many researchers appreciate that librarians are responsible for advertising the ECM service among the academic staff members and the students, research has not 
been done to determine whether publicizing the ECM service has a positive impact on the staff uptake of the ECM service.

- academic staff members - Research is not available on the attitude of the academic staff members on the ECM service and the availability of software and services other than the ECM service on the staff uptake of the ECM service.

Therefore, it can be said that a number of studies have been done to get an overall understanding of the effectiveness of digitizing course materials, however, only a limited number of studies have been done to explore the factors responsible for the effectiveness of the ECM service. 


\subsection{Research methodology and survey instruments}

Both qualitative and quantitative research methods have been used in research related to the ECM service (Biktimirov \& Klassen, 2008, p.154; Isenberg, 2006, p.167; Klyuev, Tsuchimoto \& Nikishkov, 2008; and Lowell, Christopher \& Jeff, 2003). Matthew \& Varagoor (2001) had included both multiple choice questions for quantitative analysis and open ended questions for qualitative analysis in their survey questionnaire. This ensures a better perception of the subject's attitude towards ECM services. Klyuev, Tsuchimoto \& Nikishkov (2008) state that a questionnaire is a useful instrument to get users' opinions on tools that the subjects use.

Isenberg sent a two follow-up emails to the participants 2 weeks after sending the survey questionnaire (Isenberg, 2006, p.167). It is possible to increase the response rate by sending following emails. In addition, Lowell, Christopher \& Jeff (2003) made several attempts to contact the non-respondents by phone. These approaches were considered in the development of the current research. 


\section{Research Design}

\subsection{Research methodology}

Since both qualitative and qualitative research methods seemed to be useful for the current research, both methods were selected.

Quantitative methods were selected for the current research because they provide the following advantages:

- usually involve a large number of respondents and are designed for findings that can be generalized to the whole population. Thus, quantitative methods provide an objective assessment of the phenomenon being studied

- provide a greater degree of reliability than subjective qualitative methods (Dillon, Madden \& Firtle, 1994)

- cheaper to conduct

However, quantitative methods results in a low response rate. Therefore, follow-up procedures mentioned under 3.4 had to be carried out.

Qualitative methods were useful for this study for the following reasons:

- it is possible to achieve a better understanding (Hair, Babin, Money \& Samouel, 2003) of the ECM service using qualitative research.

- the current research is the first study done to determine the factors that affect the demand for the ECM service of the University of Auckland Library. Therefore, the fact that qualitative research is flexible and enables the subjects to express themselves ensures depth and richness of information, and enables the researcher to get a deeper understanding (Deshapande, 1983, p.105) of the factors that contribute to the staff uptake of the ECM service. In addition, it was possible to obtain unexpected findings by including a qualitative approach to the research. These insights 
will be useful to expand the findings, preconceptions and frameworks of the current findings in future research (Miles \& Huberman, 1984, p. 15).

- since it was possible to get a direct account of the actual experiences of the academic staff members who use the ECM service through qualitative research, it was possible to provide strong arguments of research findings (Miles \& Huberman, 1984, p. 15).

Disadvantages of qualitative methods are

One of the major types of qualitative methods is interviews. Interviews were not selected as a research method because:

- they are relatively expensive to conduct

- they are labor intensive

- they are time consuming

- it is not possible to generalize the results to the whole population from responses obtained through interviews.

Although there are several disadvantages of qualitative research, a qualitative approach was also included into the current research because of the useful features mentioned above. Both multiple choice questions for quantitative analysis, as well as an open ended question for qualitative analysis were included in the survey questionnaire used for the current research to ensure a better perception (Matthew \& Varagoor, 2001) of the subject's attitude towards the ECM service. 


\subsection{Questionnaire}

A questionnaire was used to investigate the academic staff awareness and their attitude regarding the ECM service and the factors that contributed to the staff uptake of the ECM service. The questionnaire was designed to ensure that it was straightforward to complete. For this reason, questions 1-6 of the questionnaire were multiple choice questions, and the $7^{\text {th }}$ question was a qualitative type of question, where participants were able to provide comments on electronic delivery of course materials (Appendix 2). The $7^{\text {th }}$ question was used in the survey to provide an opportunity for the respondents to comment on the ECM service of the University of Auckland Library to get a better perception of the attitude of the academic staff members of the ECM service. Responses received for questions 1-6 in the questionnaire were used to quantitatively analyse whether factors mentioned in the problem statement contribute to the variation in demand for the ECM service by different faculties.

In addition, the questionnaires have the following advantages which made them useful for the current research:

- an online questionnaire was used for the current research. Therefore, it was cost effective.

- Lime survey software was used to create the questionnaire which enabled respondents to save their responses. This enabled the respondents to complete the questionnaire at their own pace

- it was possible to provide complete anonymity to the participants of the survey

There are several disadvantages of using questionnaires as a research tool:

- unlike in interviews, when questionnaires are used in research, the amount of control that the researcher can exercise is limited

- the researcher is usually not present when the response is completed and thus the opportunity for clarification of ambiguous aspects is minimized 
- because of lack of interviewer control, or the ability to clarify confusing points, the questionnaire cannot be complex. Clear instructions were provided on how to complete the questionnaire and uncomplicated questions were used in the questionnaire in order to avoid complexity

- questionnaires have low response rates. Non-respondents can represent a portion of the population with a particularly strong reason for not participating in the research. Not capturing their perspective can have a significantly skewing impact on the findings and might even render the research meaningless (Dillon, Madden \& Firtle, 1994). Two reminder emails were sent to the academic staff members to obtain a higher response rate.

According to literature, in many studies done to evaluate the satisfaction with online course reserves, online and paper-based surveys had been used (Biktimirov \& Klassen, 2008, p.154; Isenberg, 2006, p.167; and Lowell, Christopher \& Jeff, 2003). However, due to resource and time limitations a paper-based questionnaire was not used for the current research.

\subsection{Research population or sample}

The sample size for this research was 130 academic staff members of the University of Auckland. To get a better perception of the academic staff awareness, and the attitude of the academic staff members towards the ECM service the questionnaire was sent to 10 staff members in each of the 13 administrative units mentioned in Figure 1 in section 4.1.1. Ten academic staff members were randomly selected from University of Auckland WebPages for each academic unit. A link to the online survey was sent to the randomly selected academic staff members from different departments of the University of Auckland to reflect the needs of the diverse subjects that are taught in the University of Auckland. 


\subsection{Specific procedures}

Selected subject librarians and academic staff members from the Faculties of Education, Arts, the Tamaki Campus, and staff at CEDD were approached to get an overall idea of:

- the ECM service of the University of Auckland Library

- other services provided by the University of Auckland to digitize course materials

Information was also gathered through an intensive literature survey on research done on electronic delivery of course materials and the ECM service of the University of Auckland Library. A meeting was organized with the Assistant University Librarian, Information Commons \& Learning Services, Short Loan Manager, and the Associate University Librarian of the University of Auckland to get an overall understanding of the issues that needed addressing from the current research. A questionnaire that included both qualitative and quantitative responses was created using the collected information.

Questions similar to the questions used in the questionnaire for the current research have been used and validated in research conducted in University College in London (Secker, 2001). According to Hair et al. (2003), if the questions have been previously validated the questionnaire has to be re-validated a minimum of four times. The questionnaire was validated only five times

- since Secker, 2001 had validated and used similar questions in her research

- due to time limitations

To validate the questionnaire, it was sent to 5 selected academic staff members from 5 different departments. The questionnaire was updated using the responses that were received.

The total number of courses offered in 2008 and the number of long-distance courses offered in 2008 by each academic department or unit mentioned in section 4.3 were calculated using the University of Auckland Calendar for 2008. The correlation between the staff uptake of the ECM service, and the total number of courses offered, and the 
number of long-distant courses offered in 2008 by each academic unit was calculated using Pearson Correlation Analysis and a correlation graph.

Ethics approval was obtained from the Victoria University of Wellington to conduct the research. The ethics approval received from the Victoria University of Wellington was forwarded to the Ethics \& Biological Safety Administration of the University of Auckland to confirm that ethics approval from the University of Auckland was not necessary to conduct the research at the University of Auckland.

An online survey questionnaire was used for the current research, and a link to the questionnaire was sent online to the selected academic staff members. A brief introductory email (Appendix 1) about the survey, along with a link to the questionnaire was sent to the selected academic staff members (Appendix 2).

Secker (2001, p.23) states that there was only a $28 \%$ response rate when a questionnaire was used in a needs analysis of students of the ECM service done at the University College in London. Although the questionnaire was sent during the third week of the first semester of the University of Auckland, academic staff members receive many emails each day, and there is a high chance that the questionnaire might get overlooked and discarded. In order to ensure obtaining a higher response rate the following measures were taken in the order mentioned below:

- the First Reminder Email was sent 7 days after sending the invitation email to participate in the survey.

- the Second Reminder Email was sent 21 days after sending the first email.

- the Third Reminder Email was sent 28 days after sending the invitation email to participate in the survey.

The final date to complete the online survey questionnaire and a link to the questionnaire were included in all the emails sent to the academic staff members. There was a chance that a large number of academic staff members who do not use the service might not respond. To avoid this, in the third reminder email, the staff members who did not 
respond were informed that their responses were useful for the study even if they didn't use the ECM service.

The researcher compiled the total number of ECM requests received to digitize course materials during the academic year 2008 by each academic department or unit mentioned in figure 2 in section 4.2. The total number of ECM requests submitted to digitize course materials during the academic year 2009 and the total number of ECM requests submitted to digitize course materials by subject librarians relevant to academic units mentioned in Table 4 in section 4.4 was assembled. The correlation between the staff uptake of the ECM service and the total number of ECM requests submitted to digitize course materials by subject librarians was calculated through Pearson Correlation Analysis.

Also selected were 25 Subject Librarians who deal with different academic departments or units of the University of Auckland Library. An email was sent to them to gather facts on how they promoted the ECM service in different academic units. 


\section{Data analysis and interpretation}

\subsection{Response rate}

A total of 38 responses were received from all academic units except Tamaki. This is a $29 \%$ response rate. In general, the response rate for questionnaires can vary between 10 $60 \%$ (Sudman \& Blair, 1998, p. 165). Thus, the response rate is satisfactory to carry out a basic analysis of the staff uptake of the ECM service. However, the number of responses received from academic units such as Tamaki, Dance, Engineering, Architecture, Planning and Urban Design, Fine Arts and Visual Arts, Law, and Business are below the average response rate for this study and are not satisfactory. As a result, only limited correlations can be made between the responses received from the survey to the number of ECM requests received by the Library to digitize course materials.

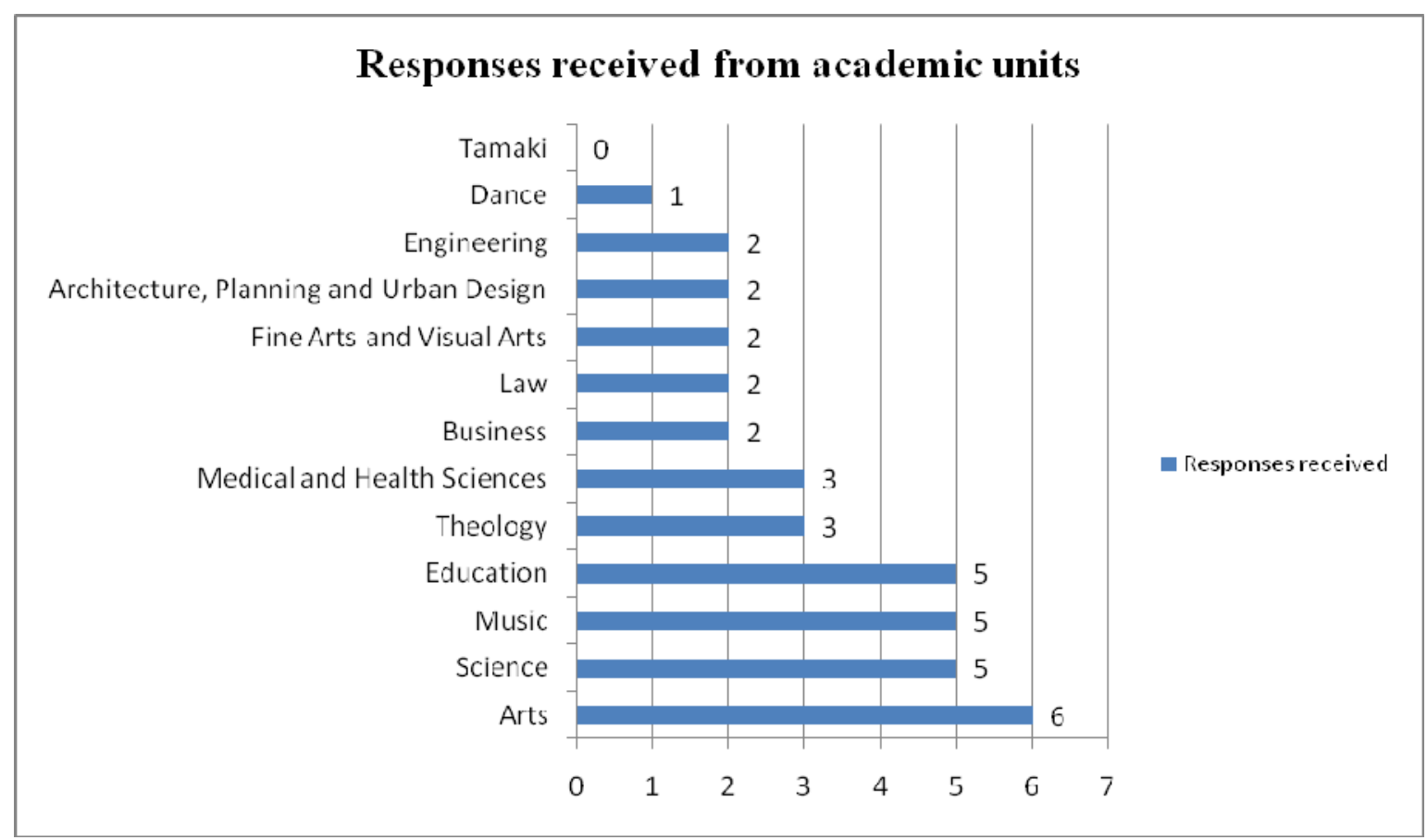

Figure 1: The number of responses received from each academic unit that were selected for the study 
There had been a $28 \%$ response rate in a similar research done at the University College London, UK. In this research a questionnaire had been sent to academic staff members only in hardcopy format (Secker, 2001, p.23). This is a considerable response rate. Technically challenged academic staff members might prefer to fill questionnaires in hardcopy format. Consequently, it would have been possible to obtain a higher response rate if the questionnaire was sent in hardcopy format as well. 


\subsection{Staff uptake of the ECM service}

Students receive a number of benefits when they can access course materials electronically (mentioned under 2.1.1). As a result of digitizing, there has been a significant increase in usage of the ECM collection in 2007.

\begin{tabular}{|c|l|l|}
\hline Year & $\begin{array}{l}\text { Total number of accesses } \\
\text { of Electronic Course } \\
\text { Materials }\end{array}$ & $\begin{array}{l}\text { Percentage } \\
\text { increase over } \\
\text { previous year }\end{array}$ \\
\hline 2006 & 362,094 & 128 \\
\hline 2007 & 826,090 & 9 \\
\hline 2008 & 900,669 & \\
\hline
\end{tabular}

Table 1: The number and the percentage increase in the total number of accesses of ECMs digitized by the University of Auckland Library.

However, the increase in 2008 is not as significant as it was in 2007 . This can be due to various barriers that students have when course materials have to be accessed electronically. Some academic staff members mentioned several concerns of providing online access to course materials:

- An academic staff member from the Theology department who used the service mentioned that he is concerned as to whether the electronic course materials are useful to students from lower socioeconomic homes who do not have broadband internet connection. He mentioned that for them the time required to download digitized materials can be considerable, making it difficult to access the course materials from home. Furthermore, Secker states that staff of the University College London were also concerned that some students might be disadvantaged if they didn't have broadband internet connections at home. Academics were concerned that accessing large documents might be slow and time consuming (Secker, 2001, p. 41). 
- Another academic staff member from the Theology academic unit who used the service commented that providing electronic access to course materials does not work for IT illiterate students, or those who have limited access to IT resources outside university campus, especially students who are enrolled in long-distance courses, and those who do not prefer to read electronic copies.

Although there was no significant increase in the total number of accesses of the Electronic Course Materials digitized through the ECM service, there had been a significant increase in the number of requests received to digitize course materials in 2008. The total number of ECM requests received to digitize course materials in 2007 was 2550 . The number increased to 2967 , in 2008 . This was a $16 \%$ increase in the number of requests received to digitize course materials. However, this increase is disproportionate among the academic units considered for this study. 


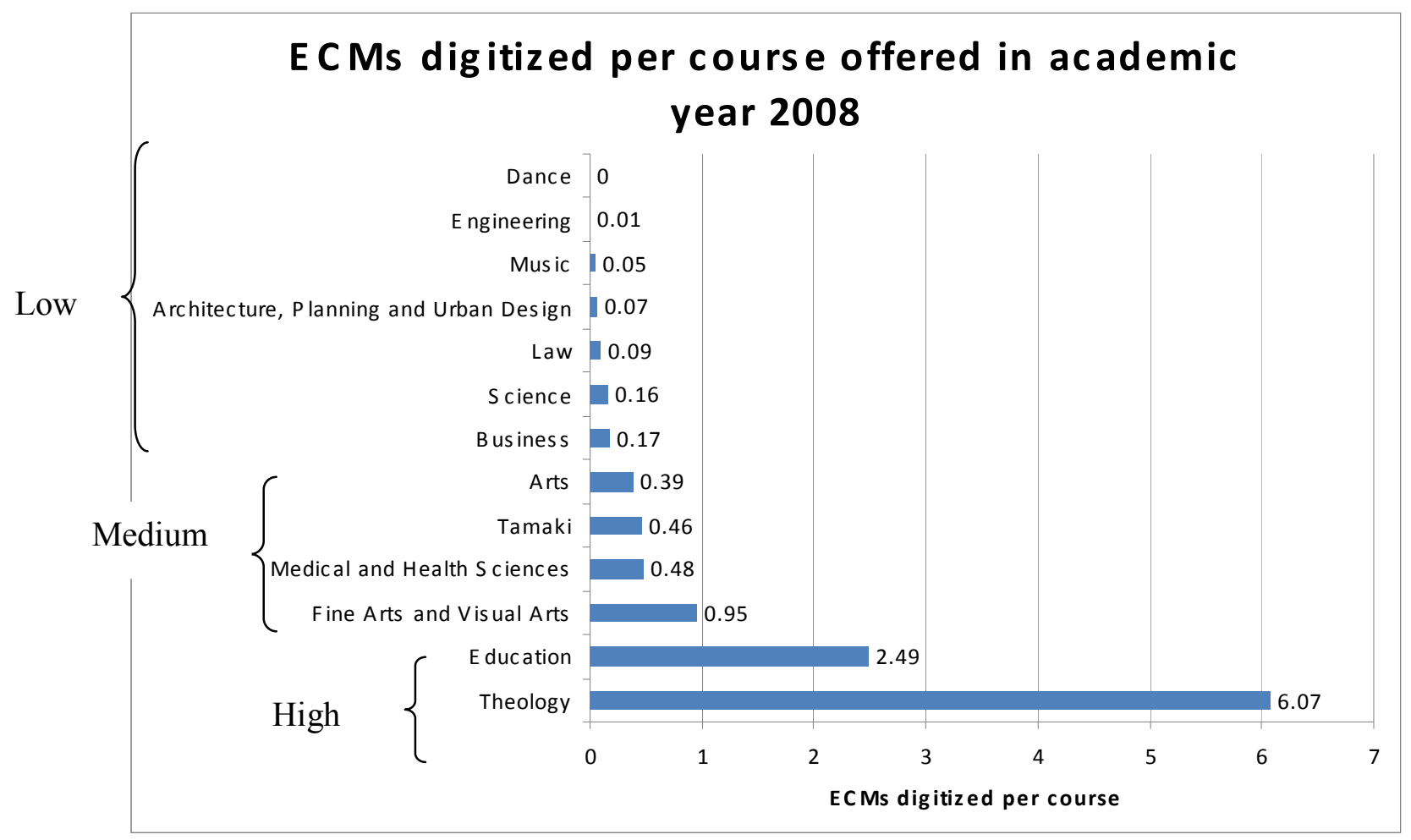

Figure 2: The number of ECMs digitized per course offered by different academic units or departments of the University of Auckland in the academic year 2008

The academic units / departments will be categorized into 3 classes according to the number of requests that were received to digitize course materials per course offered in each academic unit / department;

- Low Staff Uptake: The staff uptake of the ECM service has been extremely low in some academic departments or units such as Dance, Music, Engineering, Architecture Planning and Urban Design, Law, Science, and Business. These academic departments / units will be categorized as departments / units with Low Staff Uptake.

- Medium Staff Uptake: There has been a considerable uptake from Fine Arts and Visual Arts, Medical and Health Sciences, Tamaki, and Arts. These academic departments/units will be categorized as departments / units with Medium Staff Uptake. 
- High Staff Uptake: There has been a remarkable staff uptake of the ECM service by Faculty of Education and Department of Theology. These academic departments / units will be categorized as departments / units with High Staff Uptake. 


\subsection{The relationship between the academic staff awareness of the ECM service and the demand for the ECM service}

\begin{tabular}{|l|c|c|c|}
\hline Academic departments / Units & $\begin{array}{c}\text { Aware of, but do not } \\
\text { use }\end{array}$ & $\begin{array}{c}\text { Aware of, and } \\
\text { use }\end{array}$ & Not aware \\
\hline$*$ Theology & 1 & 2 & 0 \\
\hline$*$ Education & 1 & 3 & 1 \\
\hline$* *$ Fine Arts and Visual arts & 1 & 0 & 1 \\
\hline$* *$ Medical and Health Sciences & 0 & 2 & 1 \\
\hline$* *$ Arts & 2 & 4 & 0 \\
\hline$* *$ Tamaki & 0 & 0 & 0 \\
\hline$* * *$ Business & 0 & 0 & 2 \\
\hline$* * *$ Science & 3 & 1 & 1 \\
\hline$* * *$ Law & 1 & 0 & 1 \\
\hline$* * *$ Architecture, Planning and Urban & 1 & 1 & 0 \\
Design & 1 & 0 & 1 \\
\hline$* * *$ Engineering & 2 & 0 & 3 \\
\hline$* * *$ Music & 0 & 0 & 1 \\
\hline$* * *$ Dance & & & \\
\hline
\end{tabular}

Table 2: The number of staff members who were aware that it was possible to digitize course materials through the library

* High staff uptake

** Medium staff uptake

*** Low staff uptake

Note: Did not receive responses from Tamaki academic unit 


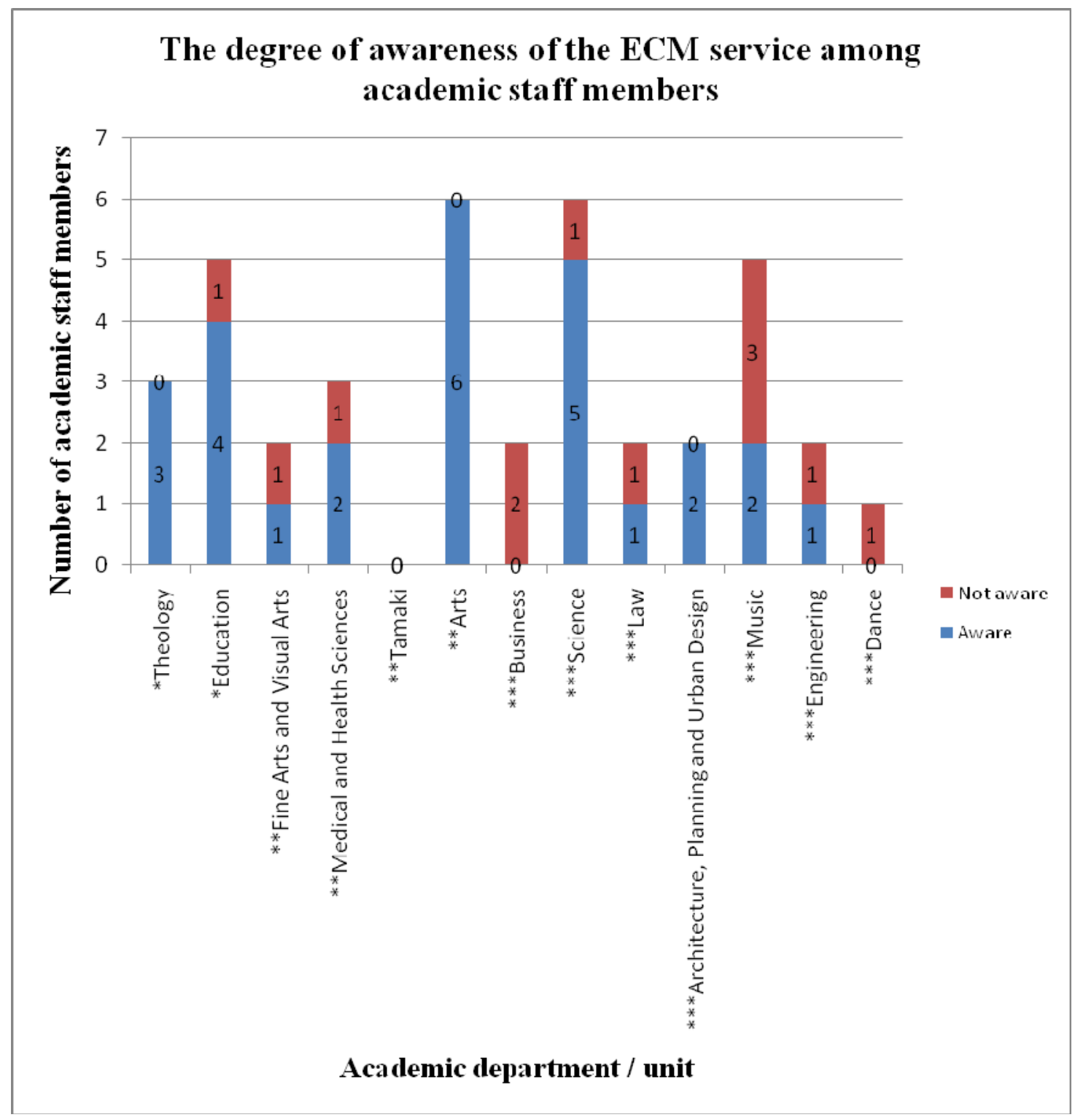

Figure 3: The number of academic staff members who were aware of the ECM service in different academic departments / units selected for the current research

* High staff uptake

** Medium staff uptake

*** Low staff uptake

Note: Did not receive responses from Tamaki academic unit 
On average, the high uptake group had $87.5 \%$ awareness, the medium uptake group had $81 \%$ awareness, and the low uptake group had $55 \%$ awareness. This shows that the staff awareness has an impact on the staff uptake of the ECM service.

\begin{tabular}{|l|c|c|}
\hline $\begin{array}{l}\text { Number of academic staff } \\
\text { members }\end{array}$ & Total & Percentage \\
\hline $\begin{array}{l}\text { who were aware of the ECM } \\
\text { service }\end{array}$ & 26 & 68 \\
\hline $\begin{array}{l}\text { who were not aware of the ECM } \\
\text { service }\end{array}$ & 12 & 32 \\
\hline Total responses & 38 & \\
\hline
\end{tabular}

Table 3: Total number and the percentage of degree of awareness of the ECM service among the academic staff members

A considerable percentage of academic staff members (68\%) who responded to the questionnaire were aware of the ECM service.

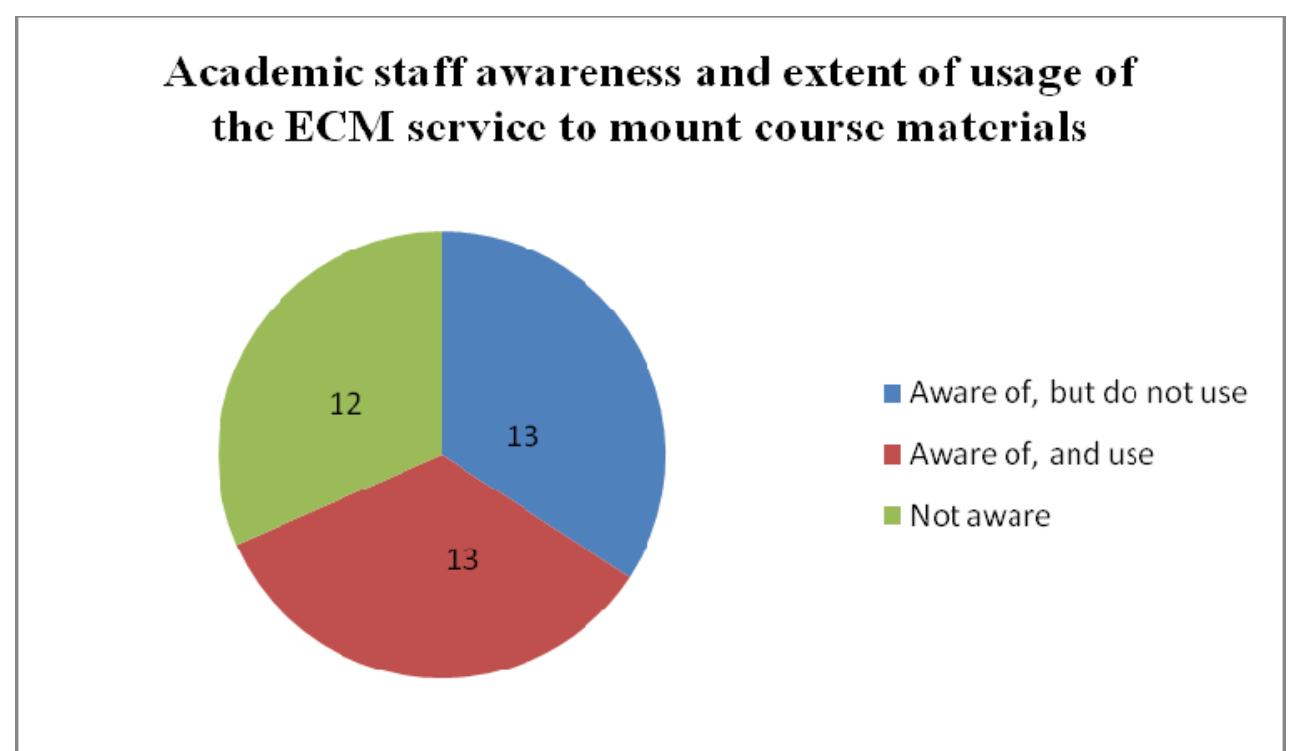

Figure 4: The extent of academic staff awareness and the usage of the ECM service to digitize course materials

It is interesting to note that $50 \%$ of the academic staff members who were aware of the ECM service did not utilize the service to digitize course materials for their courses. This 
shows that other factors other than staff awareness also have contributed to the degree of staff uptake of the ECM service. 


\subsection{The effectiveness of the promotional plan of the ECM service in each department}

\begin{tabular}{|c|c|c|c|}
\hline $\begin{array}{c}\text { Academic } \\
\text { departments / Units }\end{array}$ & $\begin{array}{l}\text { Through } \\
\text { Subject } \\
\text { Librarian } \\
\end{array}$ & $\begin{array}{l}\text { Through } \\
\text { Library } \\
\text { Website } \\
\end{array}$ & $\begin{array}{l}\text { Through other } \\
\text { academic staff } \\
\text { members who } \\
\text { use the service }\end{array}$ \\
\hline *Theology & 2 & 1 & 3 \\
\hline *Education & 4 & 0 & 1 \\
\hline $\begin{array}{l}* * \text { Fine Arts and Visual } \\
\text { arts }\end{array}$ & 1 & 0 & 0 \\
\hline $\begin{array}{l}\text { **Medical and Health } \\
\text { Sciences }\end{array}$ & 1 & 0 & 1 \\
\hline$* *$ Arts & 3 & 0 & 3 \\
\hline **Tamaki & 0 & 0 & 0 \\
\hline$* * *$ Business & 0 & 0 & 0 \\
\hline$* * *$ Science & 1 & 2 & 1 \\
\hline$* * *$ Law & 0 & 0 & 1 \\
\hline $\begin{array}{l}* * * \text { Architecture, } \\
\text { Planning and Urban } \\
\text { Design }\end{array}$ & 2 & 0 & 0 \\
\hline$* * *$ Engineering & 1 & 1 & 0 \\
\hline$* * *$ Music & 1 & 0 & 1 \\
\hline$* * *$ Dance & 0 & 0 & 0 \\
\hline Total & 16 & 4 & 11 \\
\hline Percentage & 52 & 13 & 35 \\
\hline
\end{tabular}

Table 4: The number of staff members who became aware of the ECM service through

Subject Librarians, Library Website or other academic staff members who used the service.

* High staff uptake

** Medium staff uptake

*** Low staff uptake

Note: Did not receive responses from Tamaki academic unit. The questionnaire allowed respondents to select more than one response. 


\section{Number of academic staff members who became aware of the $\mathrm{ECM}$ service through different sources}

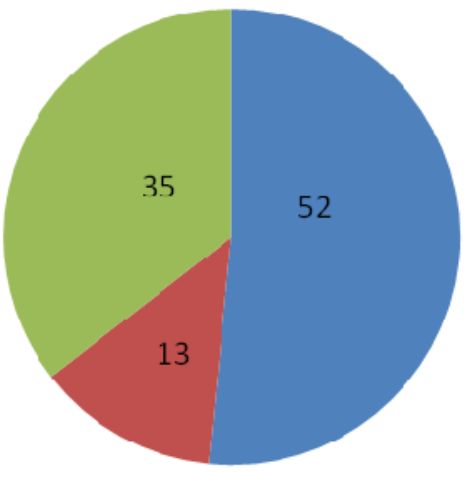

- Through subject librarian

- Library website

Through other academic staff members who use the service

Figure 5: The number of academic staff members who became aware of the ECM service through Subject Librarians of the University of Auckland, Library Website or through other academic staff members of the University of Auckland

The University of Auckland Library promotes the ECM service among the academic staff members through:

- Subject Librarians

Subject librarians appointed for different subject areas notify and update the academic staff members of the ECM service. The Subject Librarians play a vital part in promoting the ECM service, where $52 \%$ of the respondents declared that their relevant Subject Librarian was in contact with the academic staff members (Figure 5).

- Library website

The Library maintains a webpage on the ECM service at http://www.library.auckland.ac.nz/slc/ECMservice.htm. This webpage provides a general introduction on the ECM service, how to access the digitized Electronic Course Materials once they are digitized via the Course Materials Search in the Library catalogue, copyright related to digitising course materials, how to link to Electronic Course Materials from Cecil and how to make ECM requests. However, only $13 \%$ of the academic staff members who responded to the 
questionnaire indicated that they had browsed the Library Website to obtain information about the ECM service (Figure 5).

- Academic staff members

Staff members who currently use the ECM service alert their colleagues of the ECM service. $35 \%$ of the academic staff members acknowledged that their fellow academic staff members informed them of the ECM service. This demonstrates that the academic staff members who use the ECM service play an important role in promoting the service (Figure 5).

Email communications done with Subject Librarians in High and Medium Staff Uptake categories revealed that they promote the ECM service through the following activities:

- by attending faculty staff meetings

- by providing training to academic staff members on submitting requests to digitize course materials

- by introducing library services during staff orientation

- by sending reminder emails about submitting requests to digitize course materials before each semester

- by forwarding notices from Short Loan Staff of the Library to academic staff members

Several academic staff members of Education and Theology (high staff uptake) academic units, and the Medical and Health Sciences (medium staff uptake) academic unit commended the effort of their respective Subject Librarians. This confirms the significant role that the Subject Librarians play in promoting the ECM service. However, it was interesting to comprehend that Subject Librarians in Science (Low Staff Uptake) and Engineering (Low Staff Uptake) did not actively promote the ECM service.

An academic staff member of Medical and Health Sciences academic unit who used the service commended the excellent service that they receive from their Subject Librarians with respect to the ECM service. He also mentioned that he received an excellent service from the Library, and that the academic staff members have an arrangement with the library to annually update the electronic reading lists. Furthermore, he mentions that this 
procedure works extremely well, minimizing the effort and time spent on ensuring that students have the right readings at the right time for the right purpose. This staff member is referring to the Annual Weeding Project mentioned under 1.3.2. In addition, Secker also confirms that academic staff members prefer to update the course materials. Most departments have stated that it was necessary to update materials on a yearly basis (Secker, 2001, p.33).

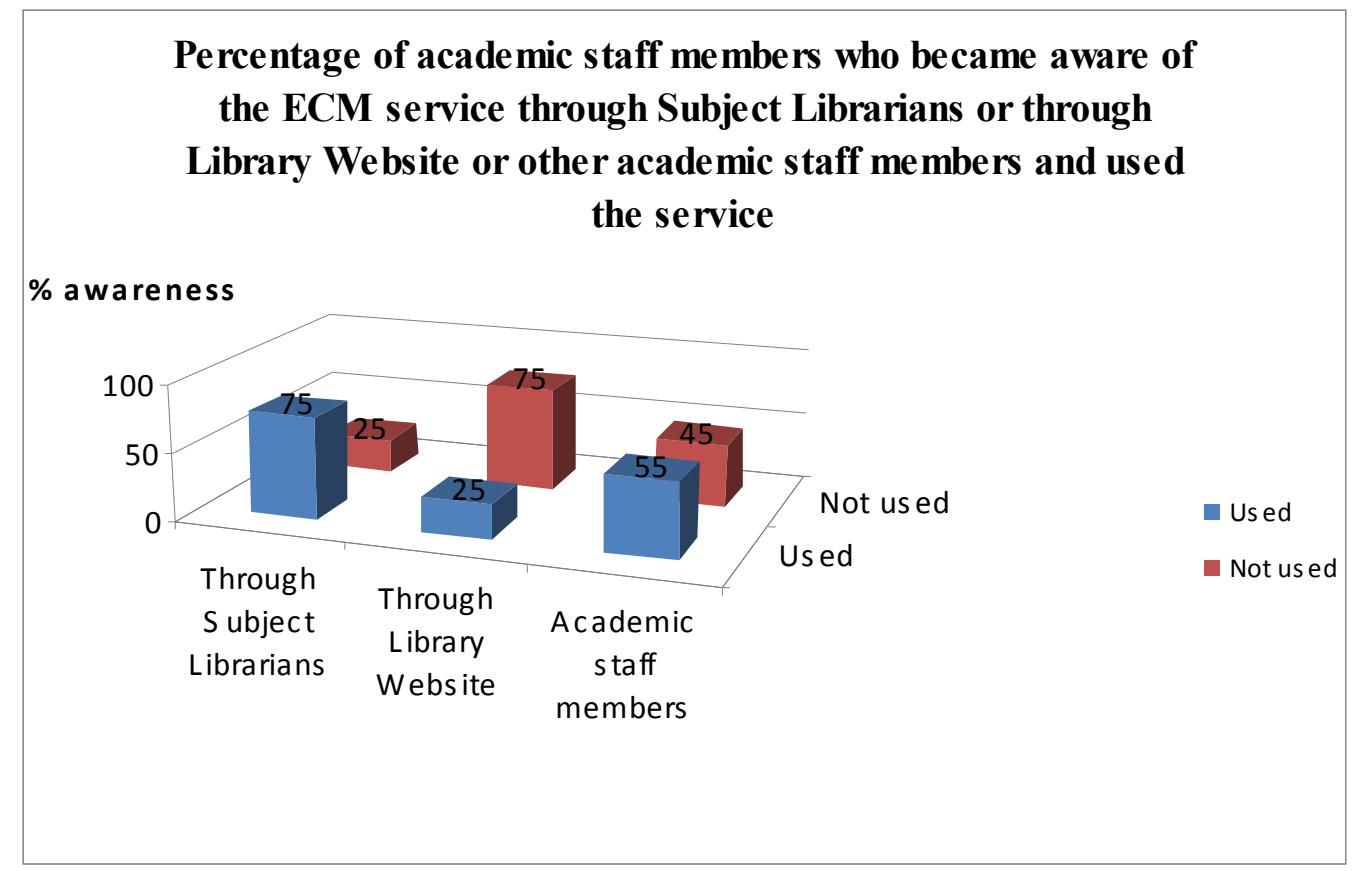

Figure 6: Percentage of academic staff members who became aware of the ECM service through Subject Librarians or Library Website or other academic staff members and used the ECM service to digitize course materials for their courses.

$75 \%$ of the academic staff members had used the ECM service to digitize course materials for their course if the Subject Librarian in the respective subject area had promoted the service to them. This confirms that the Subject Librarians provide an important service to promote the ECM service. 55\% of the academic staff members who were alerted by their colleagues of the ECM service had utilized the service to digitize course materials. 
The Library Website was less useful as a tool to promote the ECM service, where only $25 \%$ of the academic staff members who browsed the Electronic Course Materials webpage had used the ECM service. This can be due to various reasons

- Advantages of the ECM service for the academic staff members are only briefly mentioned in the webpage. The advantages are not highlighted in order to promote and attract academic staff members who have not used the ECM service before. In general, the webpage is designed to provide information, but is not designed to promote the ECM service.

- Although the University of Auckland maintains a blog, the library has not used it to promote and encourage the academic staff members to use the ECM service.

- Subject Librarians have not directed the academic staff members to the ECM webpage when they introduced the ECM service to the academic staff members. 


\begin{tabular}{|l|r|r|}
\hline $\begin{array}{c}\text { Academic Department / } \\
\text { Unit }\end{array}$ & $\begin{array}{c}\text { Number of requests } \\
\text { received to digitize }\end{array}$ & $\begin{array}{c}\text { Number of requests } \\
\text { submitted by Subject } \\
\text { Librarians }\end{array}$ \\
\hline Architecture & 3 & 0 \\
\hline Arts & 338 & 122 \\
\hline Business & 159 & 159 \\
\hline Science & 21 & 18 \\
\hline Engineering & 1 & 0 \\
\hline Law & 3 & 2 \\
\hline FineArts & 1 & 0 \\
\hline Tamaki & 31 & 0 \\
\hline Education & 1149 & 1040 \\
\hline Tamaki & 0 & 0 \\
\hline Medicine & 63 & 54 \\
\hline Pearson Correlation & & 0.98 \\
\hline Value & & \\
\hline
\end{tabular}

Table 5: The total number of requests received to digitize course materials and the number of requests that the Subject Librarians submitted for each academic unit / department between January, 2009 and end of March, 2009.

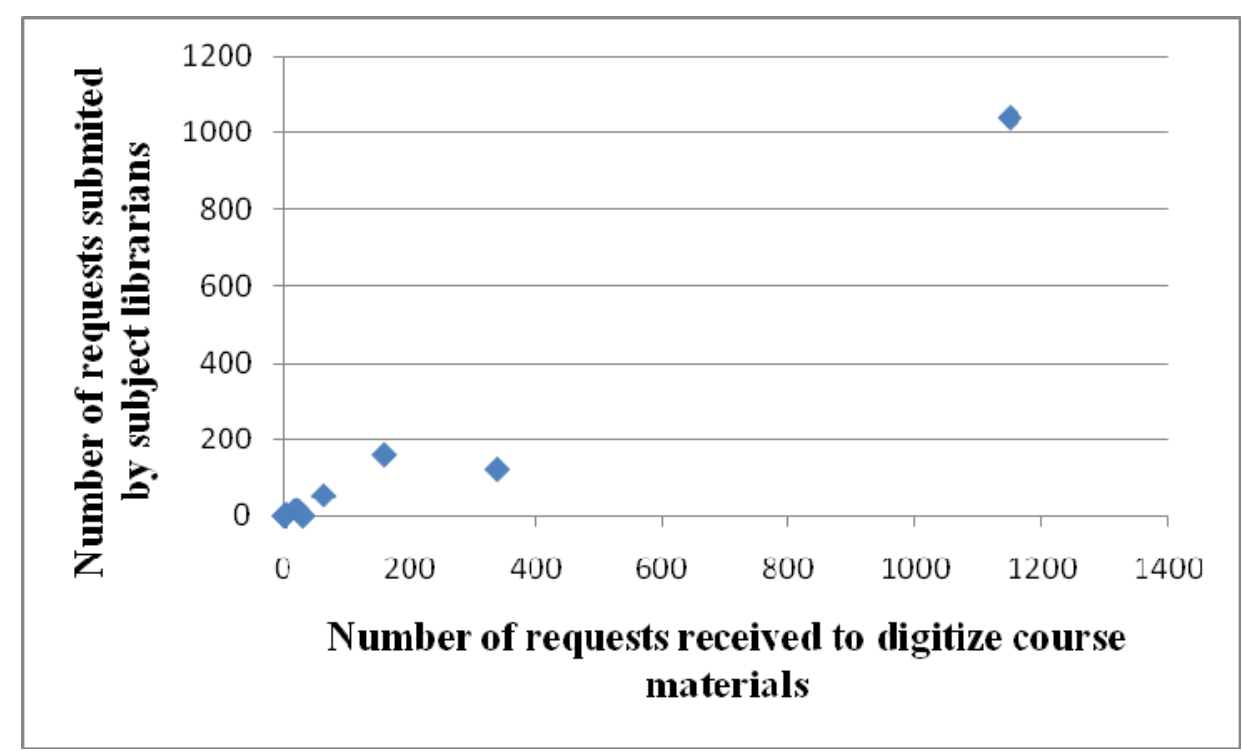

Figure 7: Correlation between the number of requests made by Subject Librarians and the total number of requests made to digitize course materials between January, 2009 and end of March, 2009. 
The Pearson correlation value for the Correlation between the number of requests made by Subject Librarians and the total number of requests made to digitize course materials between January 2009, and end of April 2009, was 0.98. This suggests a strong correlation. Figure 7 also confirms a strong correlation between the 2 parameters.

According to Young and Stokker (2001), academics vary in their use and acceptance of electronic delivery of course materials. Technically challenged academic staff members may prefer a system that is

- user friendly

- easy to submit requests to the ECM service

In the online Short Loans request forms of the University of Auckland Library the details of the academic staff member get automatically populated once the academic staff member logs in to the request form. However, the academics still have to manually enter the course details and bibliographic details. Some staff members might find this inconvenient. Secker, 2001, p.9, reported that "aside from copyright, the greatest challenges in implementing electronic reserves systems were obtaining reading lists and in-housed produced materials". The academics do not have to fill request forms when they use other services mentioned in figure 8 at the University of Auckland (discussed in detail in 4.5). The academic staff members might refrain from using the ECM service because of lack of motivation to fill requests forms to get materials digitized for their courses through the ECM service. It is possible to circumvent the barrier to obtain reading lists from academics to a certain extent when Subject Librarians submit requests to digitize course materials on behalf of academic staff members. 


\subsection{The relationship between the academic staff preference for the ECM}

service and the demand for the ECM service

The academic staff members of the University of Auckland have many services that they can use to provide access to course materials (section 1.1 for more information). This study investigated whether academic staff members who are aware of the ECM service prefer to use the ECM service.

\begin{tabular}{|l|c|c|c|c|c|c|}
\hline $\begin{array}{c}\text { Academic departments / } \\
\text { Units }\end{array}$ & $\begin{array}{c}\text { WebCT, } \\
\text { nDeva, } \\
\text { Cecil }\end{array}$ & $\begin{array}{c}\text { Course } \\
\text { Reading } \\
\text { Pack }\end{array}$ & $\begin{array}{c}\text { ECM } \\
\text { service }\end{array}$ & $\begin{array}{c}\text { Distributing } \\
\text { Reading } \\
\text { Material }\end{array}$ & $\begin{array}{c}\text { Short } \\
\text { Loan } \\
\text { collection }\end{array}$ & CEDD \\
\hline Arts & 5.3 & 5.0 & 3.7 & 2.8 & 3.3 & 1.3 \\
\hline Business & 5.0 & 6.0 & 3.5 & 1.5 & 3.5 & 1.5 \\
\hline Science & 3.5 & 5.3 & 3.5 & 4.8 & 3.3 & 1.5 \\
\hline Theology & 5.7 & 3.0 & 4.7 & 4.0 & 2.7 & 1.0 \\
\hline Law & 5.5 & 5.5 & 4.0 & 3.0 & 3.5 & 2.5 \\
\hline Fine Arts and Visual arts & 5.5 & 3.5 & 4.0 & 4.0 & 2.5 & 1.5 \\
\hline $\begin{array}{l}\text { Architecture, Planning } \\
\text { and Urban Design }\end{array}$ & 3.5 & 6.0 & 3.5 & 3.0 & 4.0 & 1.0 \\
\hline Engineering & 6.0 & 5.0 & 2.0 & 4.0 & 3.0 & 1.0 \\
\hline Music & 5.5 & 3.5 & 2.5 & 3.5 & 2.3 & 1.5 \\
\hline Education & 4.4 & 2.8 & 2.0 & 2.8 & 1.8 & 1.2 \\
\hline $\begin{array}{l}\text { Medical and Health } \\
\text { Sciences }\end{array}$ & 5.7 & 4.0 & 3.7 & 3.0 & 3.7 & 1.0 \\
\hline Dance & 4.0 & 6.0 & 2.0 & 5.0 & 3.0 & 1.0 \\
\hline Tamaki & 0.0 & 0.0 & 0.0 & 0.0 & 0.0 & 0.0 \\
\hline Average & $\mathbf{5 . 0}$ & $\mathbf{4 . 6}$ & $\mathbf{3 . 3}$ & $\mathbf{3 . 4}$ & $\mathbf{3 . 0}$ & $\mathbf{1 . 3}$ \\
\hline
\end{tabular}

Table 6: The overall preference for different methods of providing access to course materials per total number of responses received from academic staff members in different disciplines. 


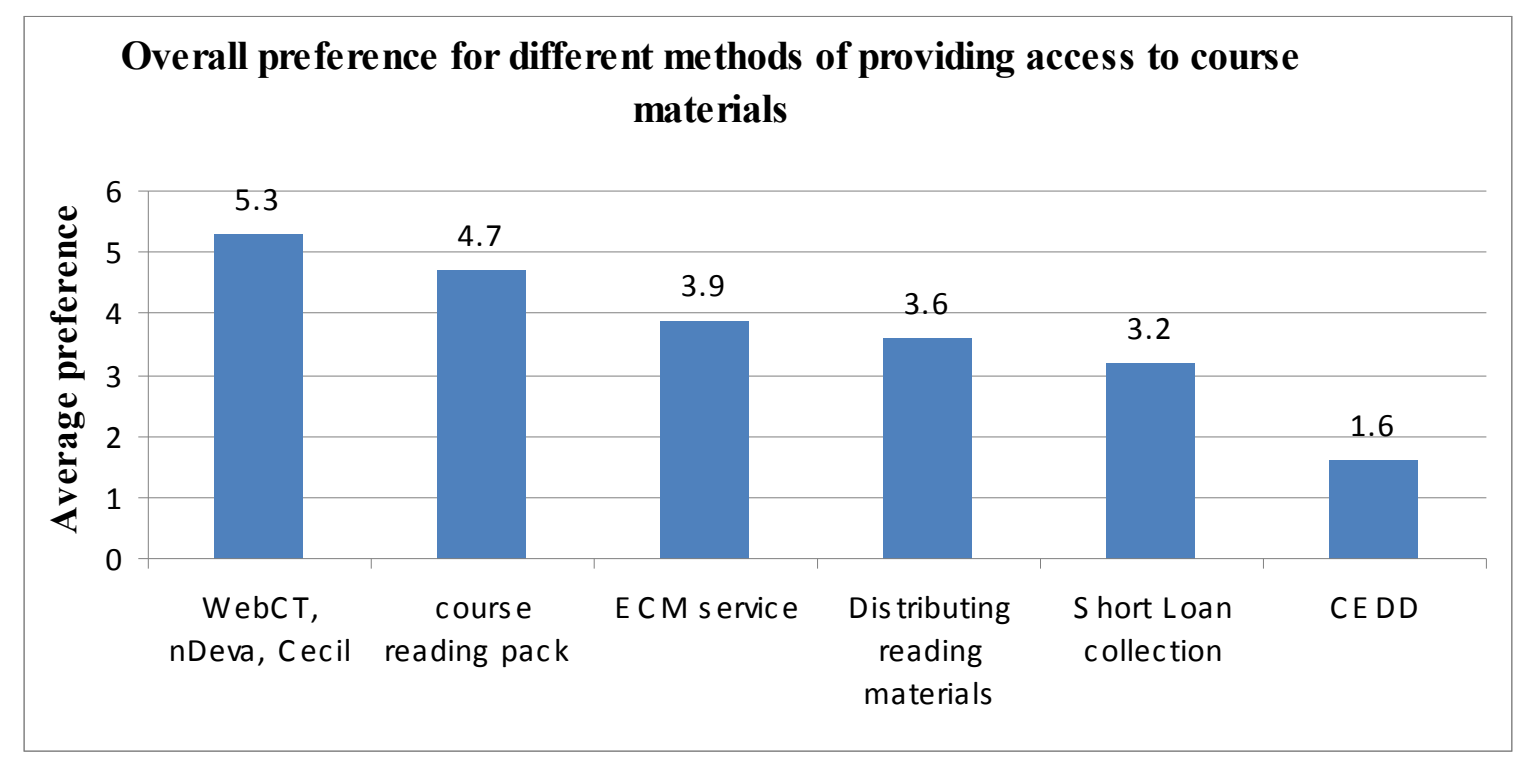

Figure 8: Overall preference for the different methods of providing access to course materials.

CEDD: Centre for Education Design and Development, Faculty of Education

According to the results obtained through this survey, the most popular mode of providing access to course materials is through WebCT, nDeva or Cecil, and by distributing course reading packs in class. When academic staff members use Virtual Learning Environment (VLE) Software such as Cecil or WebCT to provide access to course materials, the academic staff members have the advantage of utilizing the features of VLE Software to meet the specific needs of the course. Therefore, they might prefer to use the VLE as opposed to the ECM service provided by the Library. Unlike when submitting a request for a course material for digitization through the ECM service, it is not essential that the academic staff members have to fill request forms, when course materials are digitized at departmental level (where access to these materials are provided through either WebCT, nDeva or Cecil, Course reading packs, or by distributing reading materials in class), or through the CEDD of the Faculty of Education of the University of Auckland. Consequently

- technical challenges

- administrative barriers

might deter some academic staff members from using the ECM service. 
Furthermore, Secker's study revealed that departments in the University College London who used study packs had stated that the study packs service makes it easier for students to access readings, being organized into one bound volume (Secker, 2001, p.36). If it is possible to digitize all the required types of course materials through the ECM service, it is possible to provide access to all the course materials through the ECM service. However, the current ECM service digitizes only pre-published materials (discussed in detail under 4.7). Therefore, it is important to reconsider the restrictions on the types of materials that can be digitized through the ECM service and make it possible to provide access to wide variety of materials.

An academic staff member from the Faculty of Education, who was aware of and used the ECM service, commented that there are a number of different places that the students can access course materials, and that it is frustrating for students and staff. The London Business School has developed a database driven intranet with dynamically generated Course Rooms for each course. Course Rooms contain a variety of information including course outlines, class lists, discussion areas and links to course materials digitized through their ECM service. Course materials should only be provided in a secure environment for staff and students. The system has to restrict access to students in a particular course (Secker, 2001).

It is convenient for academic staff members to have a single service that fulfils their needs to digitize course materials. The database driven intranet that the London Business School enables academics to add materials into their Course Rooms. Thus, it is possible to provide access to all the course materials through the intranet (Secker, 2001, p.18). This ensures that students have a single environment to access course related materials. Consequently, this is an effective service.

The University of Auckland Library has a similar process where the Subject Librarians create resource pages and provide links to materials digitized through the ECM service. The ECM service digitizes only pre-published materials (discussed in detail under 4.7). As a result, it is not possible to provide access to all the types of course materials through 
the Resource pages. Therefore, the Course Resource pages of the University of Auckland are less effective in disseminating all the types of course materials than the database driven intranet that the London Business School uses to disseminate course materials.

Course materials are listed in the Library catalogue according to the chapter / article / report title. Because of this, several academic staff members stated that it is hard to locate course materials, particularly when there are a lot of course materials per course. They informed that they switched back to providing access to course materials through the methods that they used previously. The four academic staff members who commented on this issue stated that they would prefer that materials listed on the course reading listings be organized by author. They believe that this inconsistency between referring to works by author in handbooks or in class, and the title listings on course materials has been a constant difficulty in an otherwise helpful service. Course Resource pages are created to address this issue. However, Course Resource pages are not created for all the courses in all subject areas. The Library should take necessary actions to promote course resource pages along with the ECM service.

It was interesting to note that one academic staff member commended on the ability to filter course readings by department or e-items. However, he commented that they would like to have greater searching capacity among the database of course materials to cross reference or to improve reading options. However, the copyright license of the University of Auckland restricts access to students who are not enrolled in the course. He believed that it would be useful to have a connection between Cecil and Course Readings that are digitized through the ECM service. It is possible to provide links to ECMs through Cecil. This fact is mentioned in the Library Website. This comment further confirms that the Library Webpage on the ECM service is not efficient in disseminating valuable information about the ECM service.

An academic staff member from the Science academic unit, who was aware of the ECM service and used it, mentioned that they were notified that it is not acceptable for academic staff members to post course materials directly into Cecil due to copyright 
issues. However, email communications done with Subject Librarians and academic staff members revealed that academics continue to add course materials into Cecil. If this is not acceptable, the University management should take necessary action to restrict this. 


\subsection{The relationship between the timeliness of the ECM service and the demand for the ECM service.}

There are several steps in the ECM process (mentioned in 2.1.2). Effectiveness in each step is essential for the success of the ECM process. The ECM service of the University of Auckland Library receives a large number of requests to digitize course materials in a short span of time at the beginning of academic semesters. Thus, the turn-around time to digitize course materials increases significantly two weeks prior to, and three to four weeks after the start of each semester.

The overall turn-around time (in days) for processing requests to digitize course materials is 2 days, increasing to 6 days at peak demand. The turn-around time of the service declines during the peak demand period.

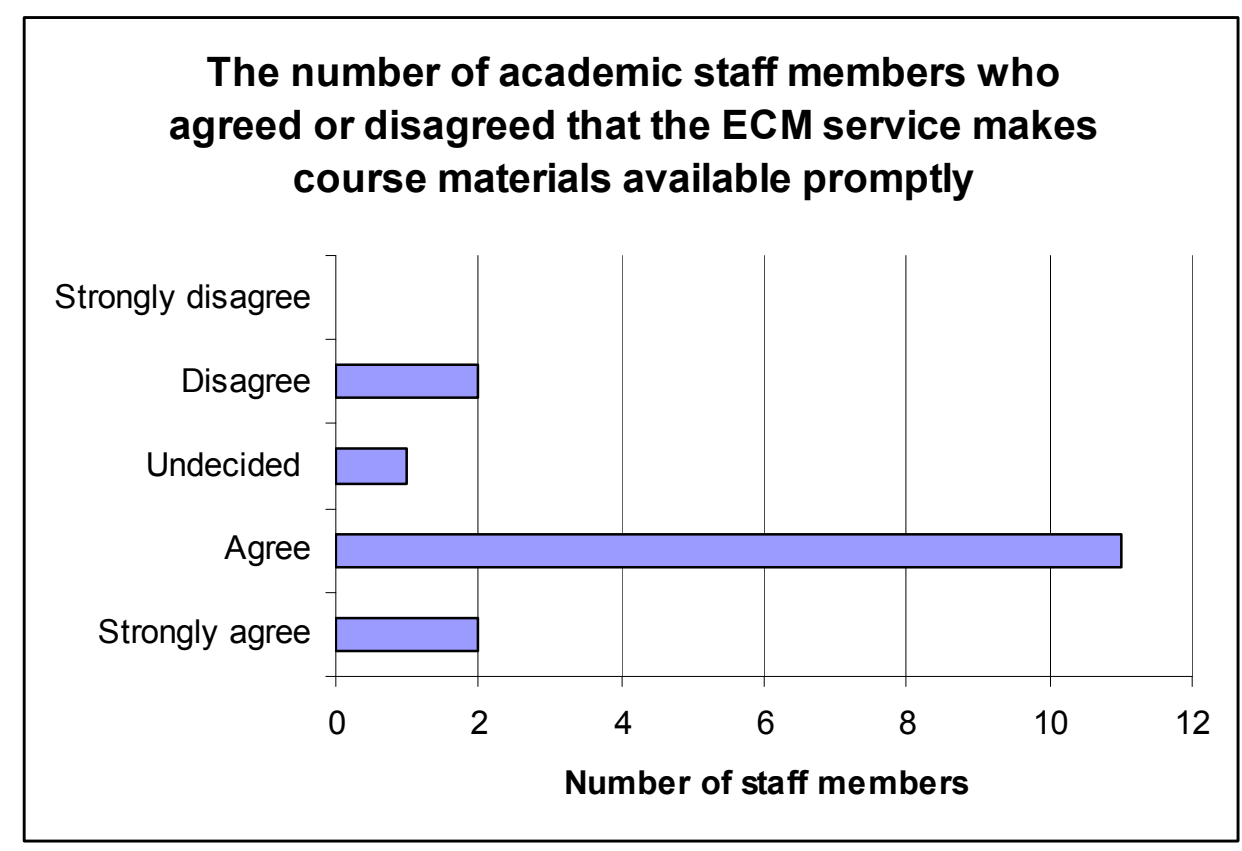

Figure 9: The number of academic staff members who agreed or disagreed that the ECM service makes course materials available promptly.

Thirteen respondents who had used the ECM service indicated that it was possible to digitize and provide access to course materials promptly. One respondent was undecided, 
and 2 respondents stated that it was not possible to provide access to course materials without delay. These results suggest that the academic staff members were satisfied with the turn-around time of the ECM service even at peak demand. An academic staff member from the Theology academic unit, who agreed that the ECM service provided access to course materials promptly, informed that the ECM service works extremely fast when they ordered material plenty of time ahead. Academic staff members who did not use the ECM service did not respond to this question. 


\subsection{The relationship between the restriction on the types of materials that can be digitized through the ECM service and the demand for the ECM service}

The ECM service of the University of Auckland mainly digitizes and provides online access to published material. The ECM service digitizes Course Content Materials that are prescribed and recommended for all the subject areas. These include

- journal articles

- book chapters

- book extracts

- conference papers

- parliamentary material

The ECM service provided by the University of Auckland Library does not include unpublished material such as:

- Model answers

- Course readers

- Collections of readings

- Student research essays/assignments

- Lecture notes

- PowerPoint slides

- Other administrative material related to courses

In addition, it is not possible to provide online access to audio and video materials through the current ECM service. These restrictions can have a detrimental impact on academic staff preference for the ECM service and the demand for the service for different subject areas. Secker (2001, p.31) has carried out a needs analysis of different types of materials needed to be digitized for different course. She states that academics use different types of course materials for courses based on the level of the course and 
subject area. The fact that different types of materials were used for courses was evident even from the current study, where academics preferred variety of course materials for their courses (Figure 10).

There is no significant relationship between the types of materials that can be digitized through the ECM service and the staff uptake (Appendix 5). 


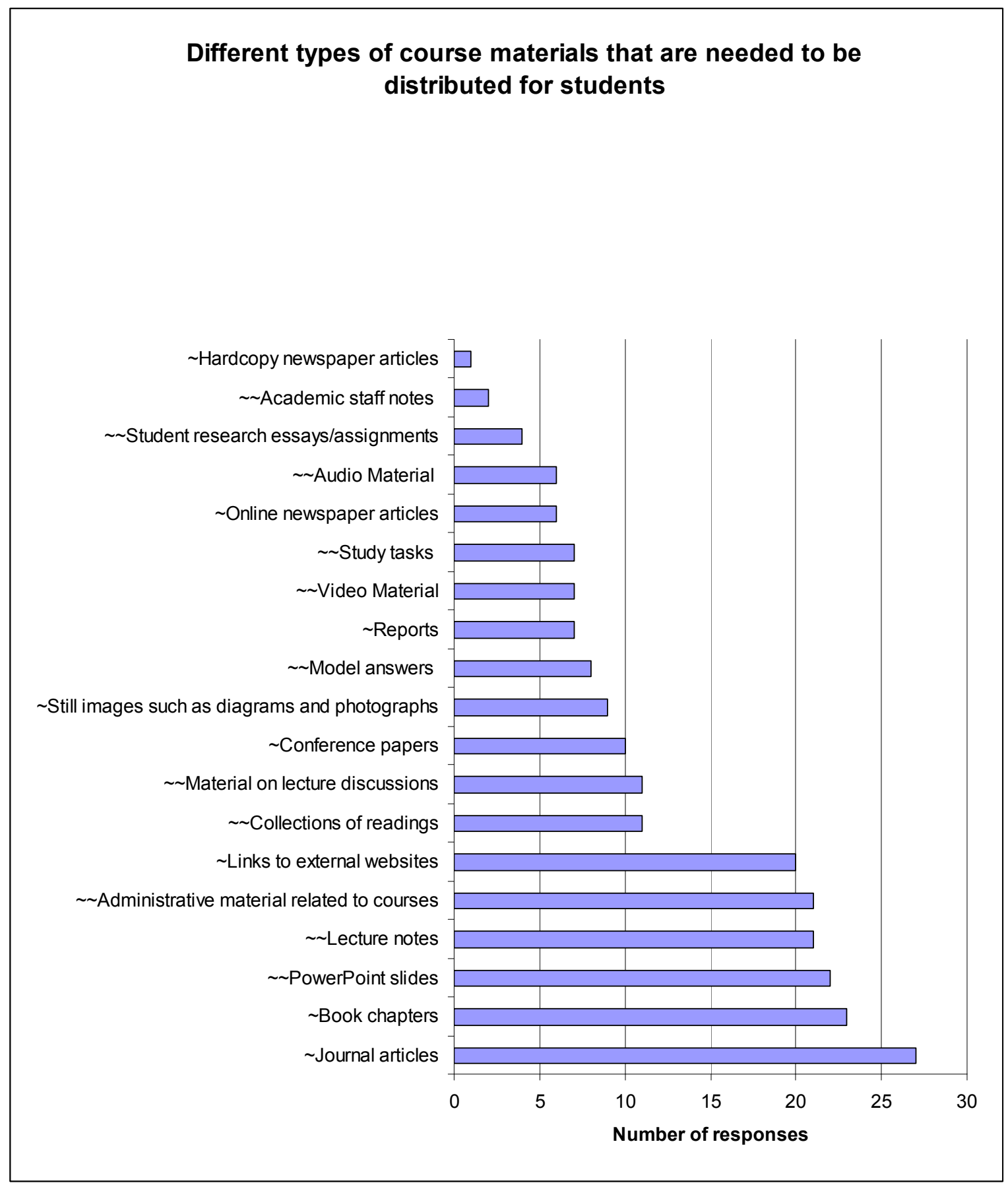

Figure 10: The number of responses received from academic staff members on the different types of course materials that are needed to be distributed to students $\sim$ Material that can be digitized through the ECM service $\sim \sim$ Materials that cannot be digitized through the ECM service 
There is a high demand to digitize materials that can already be digitized through the ECM service, such as journal articles, book chapters, links to external websites, etc. Research done by Secker (2001, p.27) confirms that journal articles and book chapters were the types of materials that were most frequently digitized. She also stated that lecturer notes, handouts, reading lists, course handbooks, and guides formed another important category. The current research revealed that there is a considerable demand for materials such as PowerPoint slides, administrative material related to courses, and materials on lecture discussion. Currently, it is not possible to digitize these materials through the ECM service.

Several academic staff members of the Music Department informed that they need to provide access to audio material. Inability to provide access to these materials may deter them from the ECM service. This would explain the low staff uptake of the ECM service from the Music Department. Furthermore, Secker reveals that the importance of audiovisual material varied tremendously across subject disciplines. She states that both audio and video materials were highly important in language departments and medical departments. Still images were useful in subjects such as medicine, biochemistry, chemistry and maths (Secker, 2001, p.32). It would be possible to increase the staff uptake of the ECM service by enabling digitizing of audio and video materials through the ECM service.

Email communications done with the Subject Librarians of the Faculty of Education revealed that all the academic staff members of the Faculty of Education were informed about submitting requests to digitize course materials prior to each semester through email. However, among the 5 academic staff members that responded to the questionnaire, one academic staff member informed that he was not aware of the ECM service, and that he used the service provided by CEDD to digitize their course materials. It could be possible that some academic staff members who digitized course materials through CEDD might ignore emails sent from the Subject Librarians. 
Some academic staff members might be interested in digitizing course materials through CEDD because it is possible to digitize a wide variety of material through CEDD. Materials that the CEDD digitize and provide online access include,

- course readings $\}$ Possible to digitize through the

- links to WebPages etc. $\}$ ECM service

- $\quad$ study tasks

- material on lecture discussions

- assessment tasks

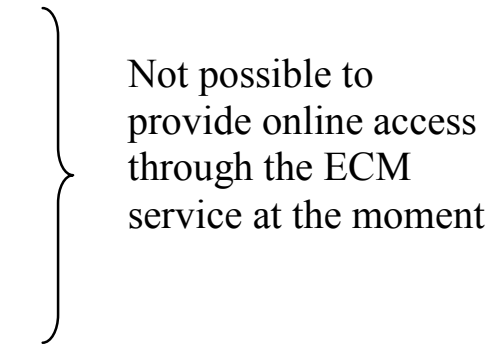

Therefore, some academic staff members might prefer the service provided by the CEDD over the ECM service.

The ECM service of the North Western University Library, Illinois digitizes a combination of lecture notes, articles and readings for courses (Secker, 2001, p.15). Consequently, the management of the University of Auckland Library should reconsider the restrictions on the types of materials that can be digitized through the ECM service. 


\subsection{The relationship between the number of online or long distant}

courses delivered by academic department / unit and the demand for the ECM service

The number of long distant and online courses offered by the University of Auckland varies among academic departments / units.

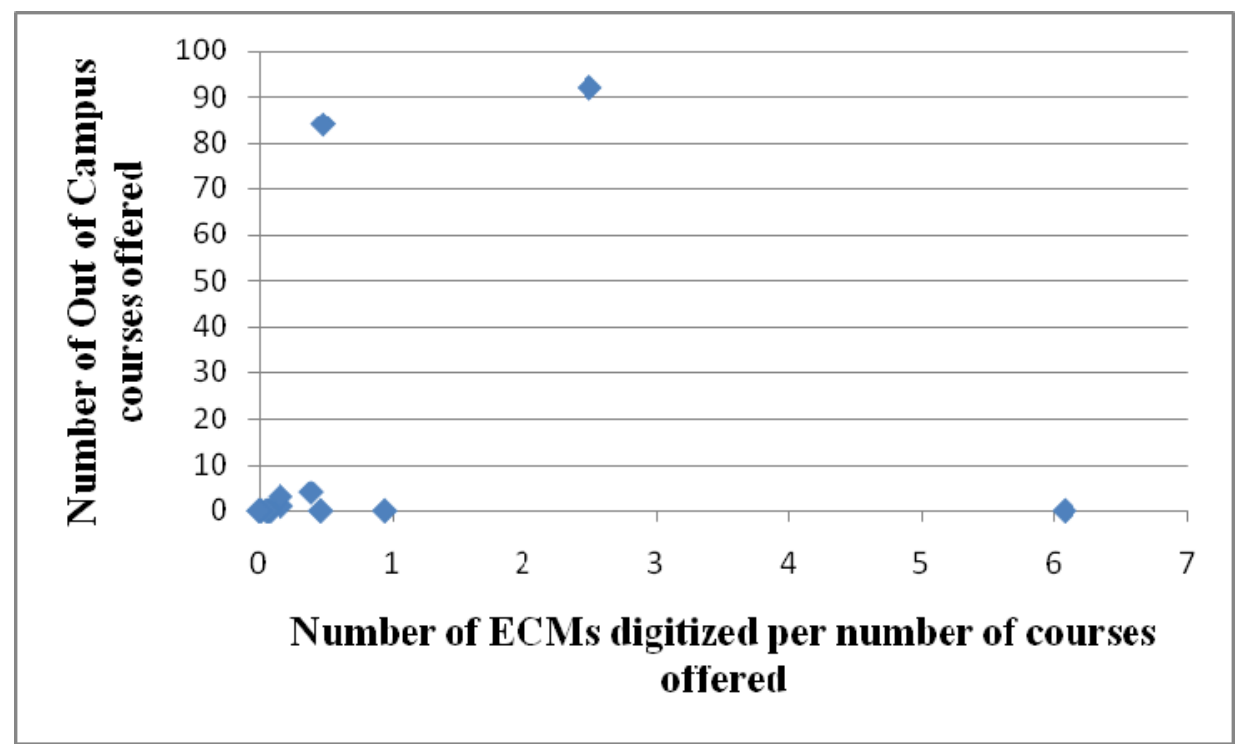

Figure 11: Relationship between the number of Out of Campus courses offered in each academic department / unit and the number of ECMs that were digitized through the ECM service per total number of courses offered by each academic department / unit. 


\begin{tabular}{|l|r|r|}
\hline Academic department / Unit & \# ECMs / C Courses & $\begin{array}{l}\text { Out of campus courses - } \\
\mathbf{2 0 0 8}\end{array}$ \\
\hline Arts & 0.393762183 & 4 \\
\hline Business & 0.167173252 & 1 \\
\hline Science & 0.163017032 & 3 \\
\hline Theology & 6.071428571 & 0 \\
\hline Law & 0.085106383 & 0 \\
\hline Fine Arts and Visual Arts & 0.946428571 & 0 \\
\hline Architecture, Planning and Urban & & 0 \\
Design & 0.070484581 & 0 \\
\hline Eng & 0.014245014 & 0 \\
\hline Music & 0.052980132 & 92 \\
\hline Education & 2.492254733 & 0 \\
\hline Tamaki & 0.463768116 & 84 \\
\hline Medical and Health Sciences & 0.482394366 & 0 \\
\hline Dance & 0 & 0 \\
\hline
\end{tabular}

Table 7: Relationship between the number of Out of Campus courses offered in each academic department / unit and the number of ECMs that were digitized through the ECM service per total number of courses offered by each academic department / unit.

The Education academic unit has a high staff uptake of the ECM service, and it is also a major distance education provider. However, the Pearson Correlation value obtained for the above correlation was 0.66 , which indicates that the 2 parameters do not have a significant correlation. 


\subsection{Other factors that contribute to low staff uptake}

ECM service is not used uniformly in all the academic departments (Figure 2). In general, academic staff members might be reluctant to provide access to course materials electronically due to various concerns.

- Some academic staff members hesitate to digitize course materials when they already have course readers prepared for their courses. They are anxious to digitize course materials due to their belief that it would take up an extensive amount of their time to set up course materials electronically. Secker also states that some departments of the University College London were concerned that it might require them to restructure the way that they delivered the course, and that they might have to undertake further work, for example to link readings to specific weeks in the course. She also affirms in her report that there was an element of resistance towards introducing changes to the current practice, especially when the change involved the introduction of new technology (Secker, 2001, p. 42). The Library should advertise that it is easy for academics to get their course materials digitized, and that all they have to do is to submit a request to digitize course materials by themselves or through their respective Subject Librarian. The Library has to be aware of these hesitant academic staff members when planning their promotional strategy of the ECM service.

- An academic staff member from the Education academic unit who was aware of the ECM service, but did not use the service to digitize course materials, commented that he did not use the service because students prefer course materials in hardcopy format since he taught in a literacy course.

- A Music academic who was not aware of the ECM service stated that it provides an easy way for students to avoid class attendance, and that implies fact-based learning, when course materials are digitized and provided through online access. However, he did not comment whether he would use the service in future or not. 
- A Theology academic staff member who occasionally used the ECM service disclosed that he believed that the Library has a policy of not keeping electronic materials for the next year that were digitized for the previous year. He stated that he had to spend extra time searching for and requesting material again should an instructor chose to use the same material in a subsequent year. The academic staff member is referring to the Annual Weeding process mentioned under 1.3.2. The library needs to be clear that the weeding process does not remove material, and that it is straightforward to reinstate them.

- Currently, Electronic Course Materials are arranged according to the title of the course material in the University of Auckland Library Catalogue. Several academic staff members have commented that this be changed so that the course materials are displayed according to the authors' name. Although it had been proposed in 2004 to change the fields displayed according to author's name, it was later revealed that this was not possible in the existing system. However, Dugdale, 1998, states that searching within the electronic reserves collection at the University of the West of England, Bristol, UK is both fast and flexible. According to Dugdale, course materials in their collection are accessed via lecturer name, module name and module number as well as by more traditional bibliographic searches. Furthermore, she states that accessing one item for a particular project automatically generates a list of other related items for the project. This flexible searching capability is impressive. Currently, the Library does not have a mechanism to restrict access to course materials through search access. The searching capacity within the electronic reserves collection in University of Western England seems impressive. The technical issues in implementing such a system should be studied in detail to find out whether this method is applicable for the University of Auckland Library electronic resource collection. 


\section{Conclusions}

\subsection{Response rate}

Responses were not obtained uniformly from all the academic units for the current research. Because of the low response rate only limited correlations can be made.

\subsection{Staff uptake of the ECM service}

- The percentage increase in usage of the ECM collection in 2008 was less significant than that of in 2007. This can be due to barriers that students have when accessing course materials electronically. According to the academic staff members who responded to the questionnaire these barriers include

○ unavailability of IT recourses outside the university

○ unavailability of broadband internet connection outside the university

○ IT illiteracy

- dislike to read electronic copies 


\subsection{The relationship between the academic staff awareness of the ECM service and the demand for the ECM service}

- There is a correlation between the academic staff awareness and the staff uptake of the ECM service (figure 3)

- $68 \%$ of academic staff members were aware of the ECM service, which is a considerable percentage (table 3 ). Nevertheless, only $50 \%$ of the academic staff members who were aware of the ECM service used it to digitize their course materials (Figure 4).

\subsection{The effectiveness of the promotional plan of the ECM service in each department}

$52 \%$ of the academic staff members had become aware of the ECM service through Subject Librarians, 35\% had become aware through their fellow academic staff members, and 13\% had become aware of the ECM service through the Library Website (Figure 5). 75\% academic staff members who became aware of the ECM service through their respective Subject Librarian used the ECM service. Thus, the Subject Librarians play an important role in promoting the ECM service. On the other hand, the staff uptake was only $25 \%$ when the academic staff members were alerted about the ECM service through the Library Website (Figure 6).

The Library Website is not efficient in promoting the ECM service. Currently the benefits of using the ECM service are mentioned briefly in the middle of the ECM service webpage. It might be possible to attract the attention of the academic staff members who browse the ECM Service Webpage by mentioning the advantages of using the service as the first information that the academic staff members notice on the ECM Webpage. The subheading, "Do I have to use the 
service?" separate this section from the rest of the information in the webpage. This subheading has to be updated in order to attract the attention of academic staff members. Additionally, the benefits of the ECM service should be mentioned, highlighting the advantages of digitizing course materials through the ECM service for academic staff members using the service.

- There appears to be a correlation between the number of requests submitted by Subject Librarians and the total number of requests submitted to digitize course materials (Figure 7). This shows that it is possible to bypass the barrier to obtain reading lists from academics (Secker, 2001, p.9) when Subject Librarians offered to submit requests to digitize course materials on behalf of academic staff members.

- Email communications carried out with Subject Librarians revealed that the University of Auckland Library does not have a standardized method of promoting the ECM service among the academic units / department of the University of Auckland.

\subsection{The relationship between the academic staff preference for the ECM service and the demand for the ECM service}

- The ECM service was the third preferred service among the services that are available for academics to provide access to course materials (Figure 8).

- Some staff members were concerned that it is confusing for students to have several places from which they could access course materials. Email communications done with subject librarians and academic staff members of the University of Auckland revealed that there is a considerable demand for adding course materials into Cecil at the departmental level. However, it is cost effective and efficient to have a centrally managed service to provide online access to 
course materials, as compared to each department setting up their own system (Guler \& Istanbullu, 2004, p.446).

Library staff have expertise in areas such as copyright law, collection maintenance, etc. As a result, the library staff are equipped to offer a better service to the stakeholders when they manage the providing of online access to course materials. Secker also concludes that there was a positive attitude towards having a centrally provided teaching support service (Secker, 2001, p.38). Therefore, the Library management should collaborate with other digitizing services of the University of Auckland in order to centralize the electronic delivery of course materials throughout the University of Auckland. Research done by Sewell (2007) (mentioned under 2.1.3) can be used as model to restructure and streamline the digitizing services of the University of Auckland Library. The Library should consider the model used by the London Business School (mentioned under 4.5) when centralizing digitizing services of the University of Auckland.

- The academic staff members selected nDeva, Cecil and WebCT as the most preferred mode of providing access to course materials. However, most of the academic staff members were not aware that it is possible to provide links in Cecil to electronic course materials that were digitized through the ECM service. This fact should be promoted widely among the academic staff members.

The Library webpage on the ECM service provides instructions at the bottom of the Webpage on how to link electronic course materials digitized through the ECM service into Cecil. This fact should be highlighted in the ECM Webpage and should be included as an advantage of using the ECM service to digitize course materials. 
- Some academic staff members commented that it is hard to locate course materials when the course materials are listed in the Library Catalogue according to the chapter / article / report title.

\subsection{The relationship between the timeliness of the ECM service and the demand for the ECM service.}

Secker reported that some academics of the University College London were concerned about the time-consuming nature of producing course materials (Secker, 2001, p.35). However, most of the academic staff members who used the ECM service of the University of Auckland Library were satisfied with the timeliness of the ECM service.

\subsection{The relationship between the restriction on the types of materials that can be digitized through the ECM service and the demand for the ECM service}

- There is no significant relationship between the restriction on the types of materials that can be digitized through the ECM service and the demand for the ECM service.

- The ECM service digitizes Course Content Material that is prescribed and recommended for all the subject areas. Biktimirov \& Klassen, 2008, have investigated the value of online support materials in hybrid courses and students' total hits on different types of course materials, such as solutions to homework problems, PowerPoint slides, etc. (Biktimirov \& Klassen, 2008, p.157). They have concluded that access to course specific files such as homework solutions is more valuable than access to online course materials in general. They have found out that providing access to course specific files was associated with better student performance. Secker states that academics from most of the departments recognized the importance of course materials that were created in-house, such as course handbooks, lecturer's handouts and notes relating to particular sessions 
(Secker, 2001, p.33). It is not possible to digitize this type of material through the current ECM service.

The Library and the academic staff members therefore need a greater understanding of the types of materials that are beneficial to enhance student performance. To acquire maximum benefits from the ECM service the management of the University of Auckland Library should consider providing electronic access to a greater range of formats through the ECM service.

\subsection{The relationship between the number of online or long distant courses delivered by academic department or unit and the demand for the ECM service}

The Education academic unit is both a major distance education provider, and has a high uptake of the ECM. However, according to the scatter graph (Figure 11) and the Pearson Correlation value, there is no significant relationship between the number of online or long distance courses offered by the University of Auckland and the staff uptake of the ECM service. This can be due to various reasons. Although the ECM service is useful for distance students, departments offering distance courses are likely to adopt their own methods of providing course materials to students.

\subsection{Other factors that contribute to low staff uptake}

It was revealed through the survey that the academic staff members had a considerable number of erroneous opinions regarding the ECM service:

- Takes up considerable amount of academic staff time to setup course materials electronically.

- It is not possible to provide links through Cecil to ECMs digitized through the ECM service. The Library has to look at making the possibility of providing more visible links. 
- The Library has a policy of discarding electronic materials that were digitized for the previous year for the next year. The Library should ensure that the academic staff members are made aware that it is possible to reinstate weeded materials on request.

- Extensive amount of their time has to be spent on setting up course materials electronically and requesting items to be digitized. The Library has to ensure that the process is simple, and that staff are aware that it is easy to get course materials digitized through the ECM service.

The Library should address the above issues through the Library WebPages, and when they promote the service through the Subject Librarians. 


\section{Recommendations}

- Develop a standard procedure for all the Subject Librarians to promote the ECM service:

- Develop a standard procedure to introduce the ECM service during Library and academic staff orientation programs.

- Incorporate practical training and information on advantages of the ECM service into training sessions and induction programs for the librarians and academic staff members.

- Develop a standard email that all the Subject Librarians can forward to academic staff members in their subject area. This email should be developed strategically to promote the ECM service. A link to the Library Electronic Course Materials webpage should be provided. This promotion should be done prior to each semester.

- Update the website strategically to promote the ECM service

- Add a FAQ section to clarify misconceptions regarding the ECM service.

- Benefits of using the ECM service should be highlighted and mentioned as the first information with a subheading that attracts the attention of academics. Include the following information as advantages of using the ECM service:

Subject Librarians create course recourses pages and provide links to course materials digitized through the ECM service

Can provide links through Cecil to course materials digitized through the ECM service 
- Advertise through the Library ECM webpage and through Subject Librarians that getting course materials digitized through the ECM service is simple and easy. Inform the academics that all that is required of the requesting academic staff member is to submit bibliographic information and the course information through an electronic request form, or simply to provide a course reading list to a subject librarian.

- Reconsider the restrictions on the types of materials that can be digitized through the ECM service within the copyright act. Enable digitizing course specific course materials through the ECM service to enhance student learning.

- Provide greater flexibility in listing course materials in the Library Catalogue and provide greater searching capacity among the database of course materials.

- Continue the Annual Weeding process. The email circulated during the Weeding process should inform the academic staff members that the course materials that are weeded can be reinstated on request. 


\section{Bibliography}

Biktimirov, E.N., \& Klassen, K.J. (2008). Relationship between use of online support materials and student performance in an introductory finance course. Journal of Education for Business. Retrieved December 20, 2008, from http://goliath.ecnext.com/coms2/summary_0198-467939_ITM

Brinkman, C. S., Lavallee-Welch, C., \& Paul, M.T. (2004). From Pilot to Program: Developing an E-Reserves Service. Kentucky Libraries, 68(2), 9-13.

Brown, D.J. (1996). Electronic publishing and libraries. London: Bowker-Sauer.

Chan, Y.E. (1992). Business strategy, information system strategy and strategic fit: measurement and performance impacts. Unpublished Doctoral dissertation, University of Western Ontario, London.

Chang, H.H. (2008). Intelligent agent's technology characteristics applied to online auctions' task: a combined model of TTF and TAM. Technovation, 28, 564-577.

Cockrill, A. (1997). Coping with changes: issues facing British and German University Libraries in the 1990's. Journal of Librarianship and Information Science, 29(2), 77-88.

Creswell, J.W. (2002). Educational research: planning, conducting and evaluating quantitative and qualitative research. Pearson Education Inc., Upper Saddle River: New Jersey.

Deshapande, R. (1983). 'Paradigm lost': on theory and method in research in marketing. Journal of marketing, 47, 101-110. 
Dillon, W.R., Madden, T.J., \& Firtle, N.H. (1994). Marketing research in a marketing environment. 3rd ed. Burr Bridge, III: Irwin.

Dugdale, C. (1998), Managing short loan collections in academic libraries: print and electronic alternatives for the new learning environment. Journal of librarianship and information science, 30, 133-140.

Feather, J., \& Marriott, R. (1993). Uncharted territory: academic libraries and the growth in the student numbers. Library review, 42 (3), 20-30.

Ferullo, D.L. (2002). The challenge of e-reserves: Donna L. Ferullo explains how copyright law is an asset in creating e-reserve programs. (strategy policy and management issues). Library Journal; Net Connect, Summer supplement, 33-35.

Guler, I., \& Istanbullu, A. (2004). Multimedia based medical instrumentation course in biomedical engineering. Journal of Medical Systems, 28(5), 447-454.

Hair, J.F., Babin, B., Money, A.H., \& Samouel, P. (2003). Essentials of business methods research. Hoboken, NJ: Wiley.

Isenberg, L. (2006). Online course reserves and graduate student satisfaction. Journal of Academic Librarianship, 32(2) 166-172.

Keefer, M.W. (2005). Making good use of online case study materials. Science and Engineering Ethics, 11, 413-429

Klyuev, V., Tsuchimoto, T., \& Nikishkov, G.P. (2008). Using a web-based system to support teaching processes. International Journal of Information and Communication Technology Education, 4(1), 72-86. 
Laskowski, M.S., \& Ward, D. (2001). Creation and management of a home-grown electronic reserves system at an academic library: results of a pilot project. Journal of Academic Librarianship, 27(5), 361-71.

Lin, T., \& Huang, C. (2008). Understanding knowledge management system usage antecedents: an integration of social cognitive theory and task technology fit. Information and management, 45, 410-417.

Lowell, M.G., Christopher, G.J., \& Jeff, E.H. (2003). The effect of interaction levels on student performance: a comparative analysis of web-mediated versus traditional delivery. Journal of Interactive Learning Research, 14(3), 285300.

Matthew, K.I., \& Varagoor, G. (2001). Student Responses to Online Course Materials. Journal of Research on Computing in Education, 33(5), 1-21.

Miles, M.B., \& Huberman, M. (1984). Quantitative data analysis: a sourcebook of new methods. Beverly Hills: Sage publications.

Neuman, W.L. (2003). Social research methods: qualitative and quantitative approaches (5th ed.). USA: Pearson Education, Inc.

Secker, J. (2001). Access to core course materials project: final report. Retrieved October, 18, 2008, from University College London Web site: http://www.ucl.ac.uk/calt/tqef/core/final.pdf

Secker, J., \& McAvinia, C. (2001). Enhancing teaching and learning at UCL: the Access to Core Course Materials Project and the Key Skills Web Development Project. Vine, 122, 35-40. 
Sewell, B. (2007). Course-related materials at the University of Denver: a collaboration: why collaborate? College \& Research Libraries News, 68(8), 514-517.

Shapiro, B. (1995). Design issues in planning electronic reserves. The Electronic Library, 13(3), 219-221.

Sudman, S., \& Blair, E. (1998). Marketing Research: a Problem-Solving Approach. Boston: McGraw-Hill.

University of Auckland (2005). Kate Edger Information Commons Short Loan Electronic Course Materials Service. Retrieved January 05, 2009, from the University of Auckland Library Web site:

http://library.intranet.auckland.ac.nz/public/intranet/slc/course_materials.asp

University of Auckland (2008). Kate Edger Information Commons Short Loan. Retrieved January 05, 2009, from the University of Auckland Library Web site: http://www.library.auckland.ac.nz/slc/

Willis, J.W. (2007). Foundations of qualitative research: interpretive and critical approaches. London: Sage publications.

Young, C., \& Stokker, J. (2001). Course materials database: integrating information resources into online teaching for students at QUT. Australian Academic \& Research Libraries, 32(3). 


\section{Appendices}

\section{Appendix 1: Cover letter of the Questionnaire

\section{Information Sheet}

Participant Information Sheet for a Study of an Electronic Course Materials Service.

Researcher: Upeksha Sajeevani Amarathunga: School of Information Management, Victoria University of Wellington

I am a Master of Library and Information Studies student at Victoria University of Wellington. As part of this degree I am undertaking a research project, the report of which will be deposited in the Victoria University of Wellington Library and Institutional Repository. I am conducting a survey among the staff members of the University of Auckland. This survey will determine the awareness of and preference for the Electronic Course Materials service by academic staff. The project title is factors affecting staff demand for an electronic course materials service. The Victoria University of Wellington requires that ethics approval be obtained for research involving human participants. You have been selected as part of a sample of academic staff to participate in this study by completing an online questionnaire. The online questionnaire is designed to investigate the preference for different methods of distributing course materials and the awareness of the Electronic Course Materials Service provided by the University of Auckland Library.

It is envisaged that the questionnaire will take about 5-7 minutes to complete. Submitting the survey will be regarded as consenting to participation. I invite you to send me an email (amaratupek@student.vuw.ac.nz) if you would like a summary of the results. Two follow-up reminders will be sent 7 and 14 days after sending the questionnaire. IP address of the participants and their details will not be captured by the on-line survey 
system to assure participants of anonymity. Responses collected will form the basis of my research project and will be put into a written report on an anonymous basis. It will not be possible to identify the participants personally. All material collected will be password protected and will be kept confidential. No other person besides me and my supervisor, Alastair Smith will see the completed questionnaires. The report will be submitted for marking to the School of Information Management and deposited in the University Library. It is intended that one or more articles will be submitted for publication in journals and conferences. The data will be destroyed two years after the end of the project.

If you have any questions or would like to receive further information about the project please contact me or my supervisor.

\section{Contact details}

The researcher of the project, Upeksha Amarathunga, Master of Library and Information Studies student and the Electronic Course Materials Library Assistant of the University of Auckland Library.

Contact: amaratupek@student.vuw.ac.nz

3737599 Extn. 89065

The supervisor of the project, Alastair Smith, Senior Lecturer of the School of Information Management, Victoria University of Wellington.

Contact: Alastair.Smith@vuw.ac.nz

Ph 6444635785

Click here to do the survey:

http://upeksha.limequery.com/index.php?lang=en\&sid=22575\&token=7am2iyf3zx59mqf 


\section{Appendix 2: Questionnaire}

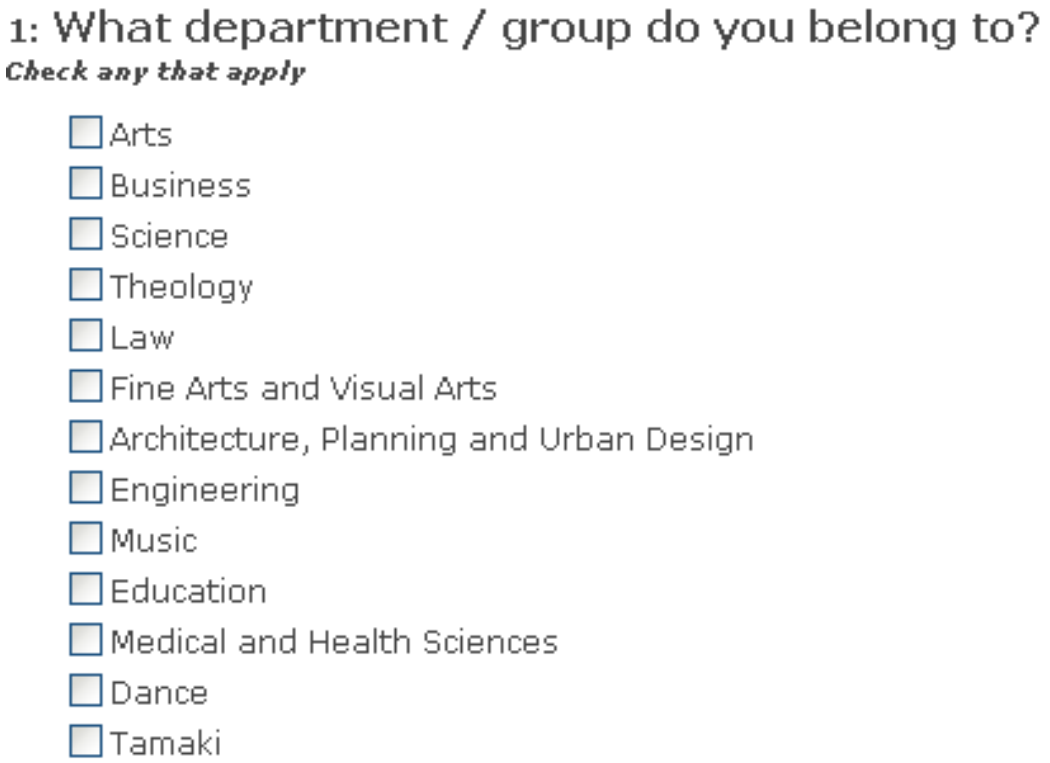

2: Are you aware of the Electronic Course Materials (ECM) service that makes it possible to digitize course materials through the library?

check any that apply

$\square$ Aware of, but do not use

$\square$ Aware of, and use

$\square$ Not aware

3: How did you become aware of the Electronic Course Materials service? check any that apply

$\square$ Through subject librarian

$\square$ Library website

$\square$ Through other academic staff members who use the service

$\square$ Other (please specify) 
4: What are different types of course materials that you distribute to students for your course? check any that apply

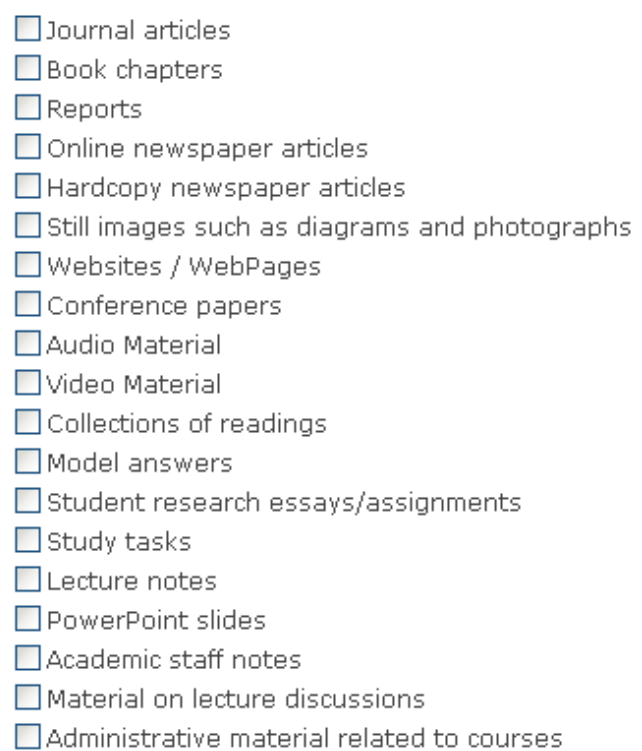

\section{5: The following are ways of providing access to course materials.}

\section{Please rank them from 1 to 6,1 being the most preferred, 6 being the least preferred}

\begin{tabular}{|c|c|c|}
\hline Your choices: & & Your ranking: \\
\hline Through WebCT / CECIL / nDeva & 1: & \\
\hline Through the Electronic Course Materials Service provided by the Library & 2: & \\
\hline $\begin{array}{l}\text { Hardcopy course materials through Library Short Loan Collection } \\
\text { Through course reading pack }\end{array}$ & 3: & \\
\hline Through the Center for Education Design and Development (CEDD) of the Faculty of Education & 4: & \\
\hline Through distributing reading materials in class & 5: & \\
\hline & 6: & \\
\hline
\end{tabular}

\footnotetext{
6:The Electronic Course Materials service makes course resources available promptly. choose one of the following answers

Strongly agree

Agree

ODisagree

Strongly disagree

(-) No answer
} 
7: Do you have any comments about online distribution of course materials?

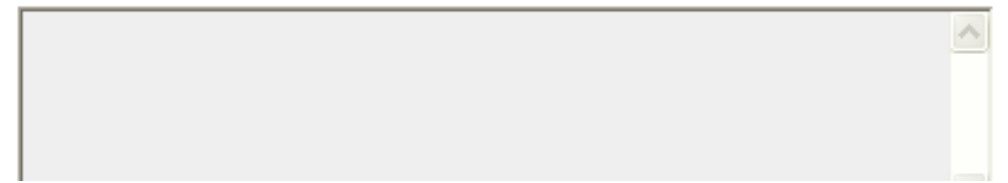




\section{Appendix 3: First and Second Reminder emails}

$\mathrm{Hi}$,

I would appreciate it very much if you could complete this survey . I know you're busy, and you may have overlooked it so far. It is envisaged that the questionnaire will take about 5-7 minutes to complete.

Your participation will be very useful, not only for my research project, but also to improve the Electronic Course Materials Service of the University of Auckland Library.

I have official support from the University of Auckland Library Management Team to carry out this research as this survey will provide vital information for the Library.

Click here to do the survey:

http://upeksha.limequery.com/index.php?lang=en\&sid=22575\&token=iry7 wb7u8xhskqy

Thank you

Sincerely,

Upeksha Amarathunga (amaratupek@myvuw.ac.nz)

\section{IT: VICTORIA}

\section{Information Sheet}

Participant Information Sheet for a Study of an Electronic Course Materials Service.

Researcher: Upeksha Sajeevani Amarathunga: School of Information Management, Victoria University of Wellington

I am a Master of Library and Information Studies student at Victoria University of Wellington. As part of this degree I am undertaking a research project, the report of which will be deposited in the Victoria University of Wellington Library and Institutional Repository. I am conducting a survey among the staff members of the University of Auckland. This survey will determine the awareness of and preference for the Electronic Course Materials service by academic staff. The project title is factors affecting staff demand for an electronic course materials service. The Victoria University of Wellington 
requires that ethics approval be obtained for research involving human participants. You have been selected as part of a sample of academic staff to participate in this study by completing an online questionnaire. The online questionnaire is designed to investigate the preference for different methods of distributing course materials and the awareness of the Electronic Course Materials Service provided by the University of Auckland Library.

Submitting the survey will be regarded as consenting to participation. I invite you to send me an email (amaratupek@myvuw.ac.nz) if you would like a summary of the results. Two follow-up reminders will be sent 7 and 14 days after sending the questionnaire. IP address of the participants and their details will not be captured by the on-line survey system to assure participants of anonymity. Responses collected will form the basis of my research project and will be put into a written report on an anonymous basis. It will not be possible to identify the participants personally. All material collected will be password protected and will be kept confidential. No other person besides me and my supervisor, Alastair Smith will see the completed questionnaires. The report will be submitted for marking to the School of Information Management and deposited in the University Library. It is intended that one or mor e articles will be submitted for publication in journals and conferences. The data will be destroyed two years after the end of the project.

If you have any questions or would like to receive further information about the project please contact me or my supervisor.

\section{Contact details}

The researcher of the project, Upeksha Amarathunga, Master of Library and Information Studies student and the Electronic Course Materials Library Assistant of the University of Auckland Library.

Contact: amaratupek@myvuw.ac.nz

3737599 Extn. 89065 
The supervisor of the project, Alastair Smith, Senior Lecturer of the School of Information Management, Victoria University of Wellington.

Contact: Alastair.Smith@vuw.ac.nz

$\mathrm{Ph} 6444635785$

To participate, please click on the link below.

http://upeksha.limequery.com/index.php?lang=en\&sid=22575\&token=iry7 wb7u8xhskqy Sincerely,

Upeksha Amarathunga (amaratupek@myvuw.ac.nz)

To participate, please click on the link below.

http://upeksha.limequery.com/index.php?lang=en\&sid=22575\&token=iry7 wb7u8xhskqy 


\section{Appendix 4: Third Reminder email}

Dear colleagues,

This survey has a few more days to run (it closes on Tuesday 5 May). I am sending this message in the hope that I can gather a larger pool of data for analysis.

Please, could you take 5-7 minutes to complete this survey on the provision of Electronic Course Materials? Your response is relevant even if you do not currently use this service in your teaching.

CLICK HERE to do the survey

http://upeksha.limequery.com/index.php?lang=en\&sid=22575\&token=iry7wb7u8xhskqy Thank you to all staff who have assisted me by responding to this survey already.

I am very grateful for your assistance

Thank you

Sincerely, Upeksha Amarathunga (amaratupek@myvuw.ac.nz)

\section{0 $\mathrm{TICTORIA}$}

\section{Information Sheet}

Participant Information Sheet for a Study of an Electronic Course Materials Service.

Researcher: Upeksha Sajeevani Amarathunga: School of Information Management, Victoria University of Wellington

I am a Master of Library and Information Studies student at Victoria University of Wellington. As part of this degree I am undertaking a research project, the report of which will be deposited in the Victoria University of Wellington Library and Institutional 
Repository. I am conducting a survey among the staff members of the University of Auckland. This survey will determine the awareness of and preference for the Electronic Course Materials service by academic staff. The project title is factors affecting staff demand for an electronic course materials service. The Victoria University of Wellington requires that ethics approval be obtained for research involving human participants. You have been selected as part of a sample of academic staff to participate in this study by completing an online questionnaire. The online questionnaire is designed to investigate the preference for different methods of distributing course materials and the awareness of the Electronic Course Materials Service provided by the University of Auckland Library.

Submitting the survey will be regarded as consenting to participation. I invite you to send me an email (amaratupek@myvuw.ac.nz) if you would like a summary of the results. Two follow-up reminders will be sent 7 and 14 days after sending the questionnaire. IP address of the participants and their details will not be captured by the on-line survey system to assure participants of anonymity. Responses collected will form the basis of my research project and will be put into a written report on an anonymous basis. It will not be possible to identify the participants personally. All material collected will be password protected and will be kept confidential. No other person besides me and my supervisor, Alastair Smith will see the completed questionnaires. The report will be submitted for marking to the School of Information Management and deposited in the University Library. It is intended that one or mor e articles will be submitted for publication in journals and conferences. The data will be destroyed two years after the end of the project.

If you have any questions or would like to receive further information about the project please contact me or my supervisor.

\section{Contact details}

The researcher of the project, Upeksha Amarathunga, Master of Library and Information Studies student and the Electronic Course Materials Library Assistant of the University of Auckland Library. 
Contact: amaratupek@myvuw.ac.nz

3737599 Extn. 89065

The supervisor of the project, Alastair Smith, Senior Lecturer of the School of

Information Management, Victoria University of Wellington.

Contact: Alastair.Smith@vuw.ac.nz

$\mathrm{Ph} 6444635785$

To participate, please click on the link below.

http://upeksha.limequery.com/index.php?lang=en\&sid=22575\&token=iry7wb7u8xhskgy

Sincerely,

Upeksha Amarathunga (amaratupek@myvuw.ac.nz)

To participate, please click on the link below.

http://upeksha.limequery.com/index.php?lang=en\&sid=22575\&token=iry7wb7u8xhskqy 
Appendix 5: Different types of course materials required for different subject areas

\begin{tabular}{|c|c|c|c|c|c|c|c|c|c|c|c|c|c|}
\hline $\begin{array}{l}\text { Types of } \\
\text { course } \\
\text { materials }\end{array}$ & $\stackrel{n}{z}$ & 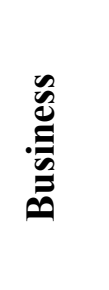 & $\frac{\mathscr{U}}{\grave{E}}$ & 苞 & ב & 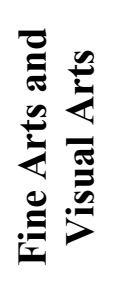 & 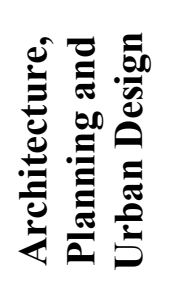 & & $\stackrel{\frac{e}{n e}}{\stackrel{e}{E}}$ & :气્气 & 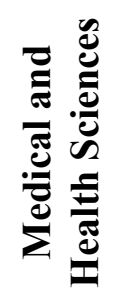 & $\stackrel{\mathscr{E}}{\stackrel{\Xi}{E}}$ & \\
\hline $\begin{array}{l}\text { Journal } \\
\text { articles }\end{array}$ & 5 & 0 & 3 & 3 & 2 & 2 & 2 & 1 & 1 & 4 & 3 & 1 & 0 \\
\hline $\begin{array}{l}\text { Book } \\
\text { chapters }\end{array}$ & 6 & 0 & 1 & 3 & 1 & 2 & 2 & 1 & 1 & 4 & 1 & 1 & 0 \\
\hline $\begin{array}{l}\text { Online } \\
\text { newspaper } \\
\text { articles }\end{array}$ & 2 & 0 & 1 & 1 & 1 & 0 & 0 & 0 & 0 & 1 & 0 & 0 & 0 \\
\hline $\begin{array}{l}\text { Hardcopy } \\
\text { newspaper } \\
\text { articles }\end{array}$ & 1 & 0 & 0 & 0 & 0 & 0 & 0 & 0 & 0 & 0 & 0 & 0 & 0 \\
\hline $\begin{array}{l}\text { Still images } \\
\text { such as } \\
\text { diagrams } \\
\text { and } \\
\text { photographs }\end{array}$ & 1 & 0 & 2 & 0 & 0 & 1 & 0 & 1 & 1 & 2 & 0 & 1 & 0 \\
\hline
\end{tabular}




\begin{tabular}{|c|c|c|c|c|c|c|c|c|c|c|c|c|c|}
\hline $\begin{array}{l}\text { Types of course } \\
\text { materials }\end{array}$ & $\stackrel{n}{2}$ & 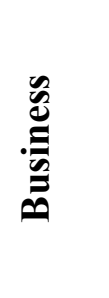 & 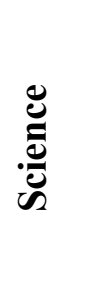 & 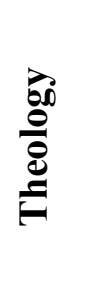 & 疍 & 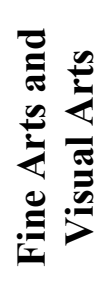 & 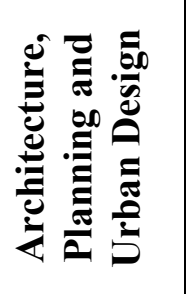 & 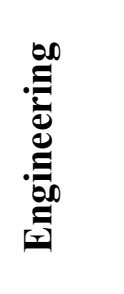 & 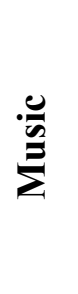 & 氖 & 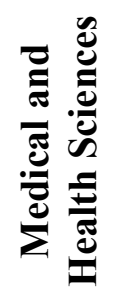 & 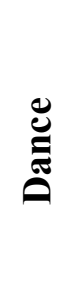 & \\
\hline Conference papers & 3 & 0 & 1 & 0 & 0 & 0 & 2 & 0 & 0 & 2 & 1 & 1 & 0 \\
\hline Reports & 1 & 0 & 0 & 1 & 1 & 0 & 1 & 0 & 0 & 2 & 1 & 0 & 0 \\
\hline Audio Material & 0 & 1 & 0 & 1 & 0 & 0 & 0 & 0 & 3 & 1 & 0 & 0 & 0 \\
\hline Video Material & 1 & 0 & 0 & 1 & 0 & 0 & 1 & 0 & 1 & 2 & 0 & 1 & 0 \\
\hline $\begin{array}{l}\text { Collections of } \\
\text { readings }\end{array}$ & 4 & 0 & 0 & 2 & 0 & 1 & 2 & 0 & 0 & 1 & 0 & 1 & 0 \\
\hline Model answers & 1 & 1 & 1 & 1 & 0 & 0 & 1 & 1 & 0 & 1 & 0 & 1 & 0 \\
\hline $\begin{array}{l}\text { Student research } \\
\text { essays/assignments }\end{array}$ & 1 & 0 & 2 & 1 & 0 & 0 & 0 & 0 & 0 & & 0 & 0 & 0 \\
\hline Study tasks & 1 & 0 & 0 & 1 & 0 & 0 & 0 & 0 & 0 & 3 & 1 & 1 & 0 \\
\hline
\end{tabular}




\begin{tabular}{|c|c|c|c|c|c|c|c|c|c|c|c|c|c|}
\hline $\begin{array}{l}\text { Types of } \\
\text { course } \\
\text { materials }\end{array}$ & $\stackrel{n}{z}$ & $\stackrel{\mathscr{0}}{\mathscr{E}}$ & 遶 & $\frac{\overrightarrow{0}}{80}$ & : & 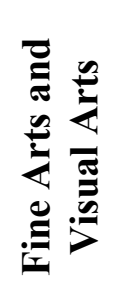 & 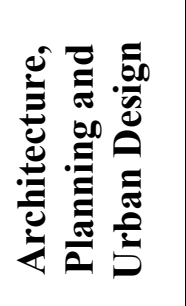 & 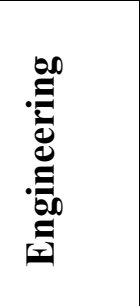 & 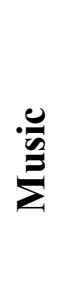 & 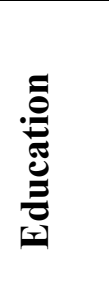 & 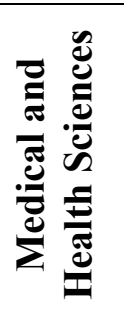 & 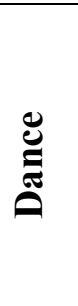 & \\
\hline Lecture notes & 4 & 1 & 3 & 3 & 0 & 0 & 1 & 1 & 1 & 4 & 2 & 1 & 0 \\
\hline $\begin{array}{l}\text { PowerPoint } \\
\text { slides }\end{array}$ & 5 & 2 & 2 & 3 & 1 & 0 & 2 & 2 & 0 & 3 & 2 & 0 & 0 \\
\hline $\begin{array}{l}\text { Academic } \\
\text { staff notes }\end{array}$ & 0 & 0 & 0 & 1 & 0 & 0 & 0 & 0 & 0 & 1 & 0 & 0 & 0 \\
\hline $\begin{array}{l}\text { Material on } \\
\text { lecture } \\
\text { discussions }\end{array}$ & 0 & 1 & 0 & 0 & 1 & & 2 & 0 & 2 & 5 & 0 & 0 & 0 \\
\hline $\begin{array}{l}\text { Administrative } \\
\text { material } \\
\text { related to } \\
\text { courses }\end{array}$ & 3 & 2 & 1 & 3 & 0 & 1 & 2 & 0 & 2 & 5 & 2 & 0 & 0 \\
\hline $\begin{array}{l}\text { Links to } \\
\text { external } \\
\text { websites }\end{array}$ & 4 & 1 & 3 & 2 & 1 & 1 & 2 & 0 & 1 & 3 & 2 & 0 & 0 \\
\hline
\end{tabular}


Upeksha Sajeevani Amarathunga

Word count : 15, 967 